\title{
Coupling between A-Type Horizontal Cells Is Mediated by Connexin 50 Gap Junctions in the Rabbit Retina
}

\author{
Jennifer J. 0’Brien, Wei Li, Feng Pan, Joyce Keung, John 0’Brien, and Stephen C. Massey \\ Department of Ophthalmology and Visual Science, University of Texas Medical School at Houston, Houston, Texas 77030
}

There are many examples of neuronal coupling via gap junctions in the retina. Of these, perhaps the best known is the extensive coupling between horizontal cells. In the rabbit retina, there are two types of horizontal cells, A-type and B-type, both of which are independently coupled. Connexin 50 (Cx50) cDNA, encoding a 440 aa protein, was successfully isolated from rabbit retina RNA. Cx50 was also obtained from isolated A-type horizontal cells (A-type HCs) by single-cell RT-PCR. A-type HCs were visualized by intracellular dye injection or with an antibody against calbindin. Confocal analysis revealed all Cx50 labeling occurred on the A-type HC matrix, typically at dendritic intersections. The $\mathrm{Cx} 50$ plaques varied in size, from punctate signals in which fine dendrites cofasciculated, to giant plaques, $>50 \mu \mathrm{m}^{2}$, in which large dendrites crossed. The numerous $\mathrm{Cx} 50$ plaques between A-type HCs may adequately account for the remarkable coupling observed in this network. We could not detect $\mathrm{Cx} 50$ staining on the tips of horizontal cell dendrites within the cone pedicle invagination. This distribution does not support a role for Cx50 in hemichannel-mediated feedback. In addition, the absence of Cx50 in B-type HCs suggests the presence of a different connexin for this cell type. In summary, these results suggest that gap junctions in the A-type horizontal cell matrix are composed from $\mathrm{Cx} 50$. Multiple neuronal connexins are expressed in the mammalian retina and different cell types express specific connexins.

Key words: retina; horizontal cells; gap junctions; connexin 50; confocal microscopy; dye coupling

\section{Introduction}

Horizontal cells are laterally extensive interneurons that provide negative feedback to cones in the outer retina and subtract a large, slow version of the visual scene. This is the basis for center surround antagonism, a common strategy in sensory systems, which helps to differentiate small, low contrast signals against a common background (Wässle, 2004). Horizontal cells are much larger than cones, but they are also famously connected via gap junctions into an extensively coupled network (Raviola and Gilula, 1975; Kolb, 1977; Vaney, 1991; Mills and Massey, 1994). Thus, the size of the receptive field far exceeds the extent of the dendritic field, and the spatial extent of the feedback signal to cones is determined, in part, by the strength of coupling in the horizontal cell network (Dacheux and Raviola, 1982; Bloomfield et al., 1995). Horizontal cell coupling is affected by several neuromodulators (Teranishi et al., 1984; DeVries and Schwartz, 1989, 1992; Hampson et al., 1994; Xin and Bloomfield, 1999; He et al., 2000). This suggests that horizontal cell coupling is plastic and that the spatial extent of horizontal cell feedback can be modulated by light intensity or circadian processes.

\footnotetext{
Received May 31, 2006; revised 0ct. 4, 2006; accepted 0ct. 5, 2006.

This work was supported by National Eye Institute Grants EY06515 (S.C.M.), EY12857 (J.0’B.), and EY10608 (Vision Core Grant). Additional support was provided by an unrestricted grant from Research to Prevent Blindness to the Department of Ophthalmology and Visual Science. S.C.M. is the Elizabeth Morford Professor of Ophthalmology and Visual Science. This paper is dedicated to the memory of Ray Dacheux.

Correspondence should be addressed to Stephen C. Massey, Department of Ophthalmology and Visual Science, University of Texas Medical School at Houston, 6431 Fannin, Houston, TX 77030. E-mail: steve.massey@uth.tmc.edu.

W. Li's present address: Department of Ophthalmology, Northwestern University Medical School, Chicago, IL 60611.

DOI:10.1523/JNEUROSCI.2296-06.2006

Copyright $\odot 2006$ Society for Neuroscience $\quad$ 0270-6474/06/2611624-13\$15.00/0
}

Gap junctions are composed of two connexons or hemichannels, one from each of two cells, which dock to form an intercellular pore. In turn, each hemichannel consists of a hexamer assembled from connexins, a family of membrane-spanning proteins with $>20$ members. Each connexin forms channels with specific pharmacology and permeation properties (Chandross et al., 1996; Guldenagel et al., 2000; Goodenough and Paul, 2003). Connexin $36(\mathrm{Cx} 36)$ appears to be the dominant neuronal connexin, but it is not expressed by horizontal cells (Deans and Paul, 2001; Feigenspan et al., 2001, 2004; Mills et al., 2001; Deans et al., 2002; Lee et al., 2003). In addition to gap junctional coupling, it has been proposed that unapposed hemichannels expressed in the dendritic tips of horizontal cells could mediate feedback to cones (Kamermans et al., 2001).

In the rabbit retina, there are two types of horizontal cell, which have different coupling properties. Dye injections reveal that A-type horizontal cells (A-type HCs) allow the passage of both Lucifer yellow and Neurobiotin, whereas B-type horizontal cells (B-type HCs) are only permeable to Neurobiotin (Vaney, 1993; Mills and Massey, 1994). This immediately suggests that the two horizontal cell networks use different connexins. In the mouse retina, axon-bearing horizontal cells with the morphological appearance of B-type HCs express Cx57, and horizontal cell coupling was eliminated in the Cx57 knock-out mouse (Peichl and Gonzalez-Soriano, 1994; Hombach et al., 2004). In this paper, we report that $\mathrm{Cx} 50$ forms gap junctions at dendritic intersections in the network of A-type HCs. The size and location of Cx50 plaques may be sufficient to account for the extensive coupling in the network of A-type HCs, and this finding explains the difference in tracer permeability between A- and B-type horizontal cells. 


\section{Materials and Methods}

Retinas were isolated from adult New Zealand rabbits as described previously (Mills and Massey, 1991). Animals were deeply anesthetized with $1.5 \mathrm{~g} / \mathrm{kg}$ urethane at $1 \mathrm{~g} / \mathrm{ml}$ intraperitoneally and killed with an overdose of $5-10 \mathrm{ml}$ of urethane at $1 \mathrm{~g} / \mathrm{ml}$ intracardially under a protocol approved by the Institutional Animal Welfare Committee of the University of Texas Health Science Center at Houston Medical School and in accordance with the guidelines of the National Institutes of Health. The orbit was infused with $2 \%$ lidocaine hydrochloride before enucleation. The retina was isolated from the sclera into oxygenated Ames medium (Sigma, St. Louis, MO) (Ames and Nesbett, 1981) and mounted on nitrocellulose filter paper (Millipore, Bedford, MA) with ganglion cell side up for intracellular injections or immunohistochemistry. Cat eyes were donated from Dr. Douglas L. Mann (Michael E. DeBakey Veterans Administration Medical Center and Baylor College of Medicine, Houston, TX) after unrelated experimental dissections and isolated as described above. Tissues were fixed in $4 \%$ paraformaldehyde in $0.1 \mathrm{M}$ phosphate buffer, $\mathrm{pH}$ 7.4, for 15-60 min and rinsed in $0.1 \mathrm{~m}$ phosphate buffer (PB), $\mathrm{pH} 7.4$, to be processed for immunohistochemistry. Retinal tissues were embedded in agarose, and sections were cut $30-50 \mu \mathrm{m}$ thick on a Vibratome (model 1000; Technical Products International, St. Louis, MO; or model VT1000 S; Leica Microsystems, Bannockburn, IL).

Reverse transcription-PCR. Total RNA was extracted from rabbit retina using an RNeasy Mini kit (Qiagen, Valencia, CA). cDNA fragments of individual connexins were cloned from rabbit retina by using reverse transcription (RT)-PCR. First-strand cDNA was made by reverse transcription with an oligo-dT primer and Superscript II reverse transcriptase (Invitrogen, Rockville, MD). First-strand cDNA was amplified with 35 cycles of PCR by using $0.2 \mu \mathrm{g}$ of each primer. PCR products were gel purified and cloned into pGEM-T vectors (Promega, Madison, WI). The sequence from the cDNA clones was analyzed with GeneRunner (Hastings Software, Hastings-on-Hudson, NY) and BLAST software (National Center for Biotechnology Information, Bethesda, MD). Cx50 primer pairs were derived based on mouse and human Cx50. Several Cx50 cDNA fragments were isolated to generate a full-length rabbit sequence. The primers used were as follows: (1) forward, 5'-CTTGGAGGAGGTGAATGAGC-3' ${ }^{\prime}$, and reverse, $5^{\prime}$-TGATGTGGCAGATGTAGGTC3'; (2) forward, 5'-GTGGGTGAGAAATGGGCG-3', and reverse, 5'-TGGTTGCTCTACAGGCCTCTTG-3'; (3) forward, 5' -CAAGAGGCCTGTCGAGCAGCCC-3', and reverse, 5'-TCATACGGTTAGATCGTCTGACCTG-3'.

Single-cell RT-PCR. Superior rabbit retina was dissected in Ames medium and placed on filter paper, ganglion cell side up. The following dissociation procedure was performed in a sterile tissue culture facility. Retina was rinsed twice for $5 \mathrm{~min}$ in sterile aerated HBSS without calcium or magnesium (Invitrogen). An enzyme mixture of papain was activated $30 \mathrm{~min}$ before retina dissection ( $5.5 \mathrm{~mm}$ cysteine, $2.5 \mathrm{~mm}$ EDTA, and 25 $\mathrm{mg}$ of papain, $\geq 14 \mathrm{U} / \mathrm{mg}$ protein) (Sigma) in $10 \mathrm{ml}$ of HBSS. Tissue was placed in $5 \mathrm{ml}$ of enzyme mixture for $15 \mathrm{~min}$ at $37^{\circ} \mathrm{C}$, removed from filter paper, and shaken at room temperature for $20 \mathrm{~min}$ in $5 \mathrm{ml}$ of fresh enzyme mixture. The papain enzyme digestion was stopped by placing the retina for $5 \mathrm{~min}$ in $10 \mathrm{ml}$ of HBSS solution containing 20\% fetal bovine serum (FBS) (Invitrogen). The retina was cut into fragments and mechanically dispersed by trituration in $2 \mathrm{ml}$ of HBSS solution with $10 \%$ FBS, $1 \mathrm{~mm}$ calcium chloride, $1 \mathrm{~mm}$ magnesium chloride, and $0.2 \%$ DNAase I (Sigma). Dissociated cells (100 $\mu \mathrm{l})$ were spread out in a $35 \mathrm{~mm}$ small dish with $2 \mathrm{ml}$ of Dulbecco's PBS (Invitrogen).

Individual A-type horizontal cells were identified by their typical morphology and collected with a micropipette. The tip of the pipette was broken and contents were then expelled into a $0.5 \mathrm{ml}$ microcentrifuge tube containing RNaseOut, random hexamers (50 ng) and dNTPs (Superscript First Strand Synthesis System for RT-PCR; Invitrogen). To start reverse transcription, tubes were incubated for $30 \mathrm{~s}$ at $65^{\circ} \mathrm{C}$, chilled on ice, and supplemented with a solution that contains buffer, $\mathrm{MgCl}_{2}, \mathrm{DTT}$, and DEPC-water (Superscript First Strand Synthesis System for RTPCR; Invitrogen, Rockville, MD). After incubation at room temperature for $2 \mathrm{~min}$, Superscript II reverse transcriptase (Invitrogen) was added, and cDNA synthesis was performed at $42^{\circ} \mathrm{C}$ for $50 \mathrm{~min}$ and terminated by incubating at $70^{\circ} \mathrm{C}$ for $15 \mathrm{~min}$. Two rounds of PCR amplification were performed with the second primers nested within the first primer set. Primers were based on the Cx50 sequence in the rabbit retina. For the first round, the forward primer was 5'-CACCAAGAAGTTCCGGCTGGAG-3' and the reverse primer was 5'-ATGGAGGAGACAGCAATGGAG- $3^{\prime}$. For the second round, the forward primer was 5'-GGACCTACATCTGCCACATCATC- 3 ', and the reverse primer was 5'-TGGTTGCTCTACAGGCCTCTTG. Second-round PCR products were analyzed by gel electrophoresis. The expected size of the amplified cDNA is $284 \mathrm{bp}$

Western blot. Tissues were isolated from multiple organs that are known to contain connexins, such as heart, lung, liver, and lens as well as retina. The tissues were sonicated in homogenization buffer $[0.32 \mathrm{~m} \mathrm{su}-$ crose, 2 mM EGTA, $5 \mathrm{~mm} \mathrm{MgCl}_{2}, 10 \mathrm{~mm}$ Tris, $\mathrm{pH}$ 7.4, and a proteinase inhibitor mixture (1:100; Sigma)] and centrifuged at $1700 \times g$ for $10 \mathrm{~min}$ to remove large particulates. The supernatant was removed and centrifuged at $38,000 \times g$ for $1 \mathrm{~h}$ to isolate a membrane fraction. Homogenates of rabbit tissues were quantified with a protein assay. Rabbit proteins $(20-60 \mu \mathrm{g})$ were separated by SDS-PAGE and transferred to either nitrocellulose membranes (Bio-Rad, Hercules, CA). The membranes were blocked with $4 \%$ powdered milk in $1 \times$ TBS-T $(0.32 \mathrm{M}$ sodium chloride, $2.68 \mathrm{~mm}$ potassium chloride, $25 \mathrm{~mm}$ Tris, $0.05 \%$ Tween 20 ) for $1 \mathrm{~h}$ at room temperature and probed with the connexin antibodies plus $4 \%$ milk in $1 \times \mathrm{TBS}-\mathrm{T}$ at $4^{\circ} \mathrm{C}$ overnight. Membranes were then washed in $1 \times$ TBS-T and probed with secondary antibodies conjugated to horseradish peroxidase (1:2000) in 4\% milk in $1 \times$ TBS-T. Labeled bands were detected by chemiluminescence (Pierce Biotechnology, Rockford, IL.).

Primary antibodies that were used for Western blot analysis include rabbit anti-Cx40 (1:250; Chemicon, Temecula, CA) that cross-reacts with Cx50-CT and rabbit anti-Cx50-IL (1:500), donated by Dr. Thomas W. White (State University of New York, Stony Brook, NY) (White et al., 1992). The 19 aa peptide sequence used to generate the Cx40 antibody from Chemicon shares 16 aa (84\%) with rabbit Cx50 sequence in the carboxyl terminus, and will be referred to as $\mathrm{Cx} 50-\mathrm{CT}$.

Intracellular injections and immunohistochemistry. Isolated pieces of live retina with sclera attached were incubated in DAPI (4,6-diamino-2phylindole) to visualize cells, and then mounted ganglion side up on filter paper. Individual cells were filled with both $4 \%$ Neurobiotin and $0.5 \%$ Lucifer yellow-CH or with Alexa 568 hydrazide. The Alexa 568 hydrazide has very low permeability through gap junctions. The retina was perfused for $5 \mathrm{~min}$ more to permit cellular diffusion, fixed in $4 \%$ paraformaldehyde for 30-45 min, and then washed several times with $0.1 \mathrm{M} \mathrm{PB} / 0.5 \%$ Triton $/ 0.1 \% \mathrm{NaN}_{3}$.

Retinal tissues were blocked in 3\% donkey serum and incubated in primary and secondary antibody dilutions, made in $1 \%$ donkey serum/ $0.1 \mathrm{M} \mathrm{PB} / 0.5 \%$ Triton$/ 0.1 \% \mathrm{NaN}_{3}$. Primary antibodies were incubated at $4^{\circ} \mathrm{C}$ for 5-7 d, and secondary antibodies were incubated at $4^{\circ} \mathrm{C}$ overnight. Antibodies were applied and developed sequentially in experiments using two antibodies from the same species. Tissues were blocked between sequential antibody incubations with unconjugated, Fab monovalent fragments. The primary antibodies included the following: rabbit antiCx50 (1:500; gift from Dr. Thomas W. White); rabbit anti-Cx40 (1:2501:500; Chemicon); mouse anti-calbindin, clone CB-955 (1:200; Sigma); mouse anti-calbindin, clone CL-300 (1:100-1:200; Abcam, Cambridge, MA); rabbit anti-calbindin (1:5000; Swant, Bellinzona, Switzerland); goat anti-glutamate receptor 5 (GluR5) (1:100; Santa Cruz, Santa Cruz, CA); and rabbit anit-GluR2/3 (1:100; Chemicon).

Imaging. Zeiss (Oberkochen, Germany) LSM-410 and LSM-510 Meta confocal microscopes were used to image retinal whole mounts in which tracer dyes and antibodies were labeled with Cy3, Cy5, or Alexa 488 conjugated to streptavidin or secondary antibodies, raised in donkey (Jackson ImmunoResearch, West Grove, PA; Invitrogen). Images were usually presented as short stacks of $5-10 \times 0.3-0.5 \mu \mathrm{m}$ sections to include structures of interest and flatten the tissue. Alignment was checked with fluorescent $1 \mu \mathrm{m}$ latex beads (Invitrogen) and resolution was estimated as $0.3 \mu \mathrm{m}$ in $x y$ and $0.5 \mu \mathrm{m}$ in the $z$ dimension. Digital images were acquired from the confocal microscope with 40 or $63 \times$ objectives and processed in Adobe Photoshop (Adobe Systems, San Jose, CA) to enhance brightness and color. Structures of interest (Cx50 plaques) were 
selected, aligned, and averaged to evaluate possible colocalization with neighboring structures (A- or B-type HCs) (Li et al., 2002). No filtering was applied to the images presented.

Quantitative analysis. The size analysis was conducted for two-dimensional plaques found in stacked projections, usually $10-20 \times 0.3-$ $0.5 \mu \mathrm{m}$ sections, to image the band of HC processes and flatten the tissue. Gap junction plaques may have three-dimensional (3D) structure, but no attempt was made to correct for this in the size analysis. Nevertheless, most giant plaques were planar in whole-mount view, probably because they occur between overlapping major A-type HC dendrites. The errors associated with 3D structure may lead to a minor underestimate of gap junction size but should have little effect on the range of sizes encountered.

We wanted to determine the Cx50 plaque sizes to estimate the possible functional roles. Signals $<0.1 \mu \mathrm{m}^{2}$ may be below the resolution limit $(\sim 0.3 \mu \mathrm{m})$ and were excluded. To obtain size distributions of $\mathrm{Cx} 50$, images were analyzed using MatLab, version 5.3 (The MathWorks, Natick, MA), and Sigma Scan Pro 4 (Systat Software, Point Richmond, CA). All images used for statistical comparisons were taken with similar settings on the confocal microscope. A signal intensity threshold was applied to images to decrease the enlargement of plaque sizes by optical blur. Because all contiguous pixels of a given intensity were selected in Sigma Scan Pro 4 software, a threshold was required to easily differentiate signals that were above background. The threshold of 60 that was used for image analysis of whole-mount tissues was based on the intensity of pixels at the edge of a $\mathrm{Cx} 50$ plaque.

In MatLab, signals with color intensities $>60(60-255)$ were extracted and replotted in a new image. The new image was imported into Sigma Scan Pro 4, and individual plaques were highlighted to determine their pixel number and size. Plaque sizes were sorted into groups in MatLab, and those $>0.1 \mu \mathrm{m}^{2}$ were used in the distribution analysis. For the distribution of Cx50 plaques per cell, 12 images were acquired from three retinas, all in inferior retina $\sim 3.6 \mathrm{~mm}$ from the myelinated band $(1 \mathrm{~mm}$ from visual streak) and $0.6-3.2 \mathrm{~mm}$ from the optic nerve. For distribution along superior and inferior axes, images were taken $2 \mathrm{~mm}$ lateral to the optic disk, in $1 \mathrm{~mm}$ steps from the visual streak. For overall superior versus inferior distribution, images were acquired using a $40 \times$ objective: regions in far peripheral retina ( $>5 \mathrm{~mm}$ from myelinated band) were selected based on calbindin labeling, rather than Cx50 labeling.

\section{Results}

Gap junctions in A-type horizontal cells pass Lucifer yellow

In the rabbit retina, as in many mammalian species, there are two types of horizontal cell. A-type HCs are axonless with large asymmetrical dendrites that contact cones (Raviola and Dacheux, 1990; Vaney, 1991; Mills and Massey, 1994). In contrast, B-type HCs have more numerous, symmetrical dendrites that also contact cones, and a long axon that expands into an elaborate axon terminal. The fine branches of the axon terminal selectively contact rods (Nelson et al., 1975; Boycott et al., 1978; Bloomfield and Miller, 1982).

A-type HCs are extremely well coupled. This can be observed after the intracellular injection of Neurobiotin, when a network of thousands of dye-coupled horizontal cells may be obtained. The gap junctions between A-type HCs are unusual, because they are also permeable to Lucifer yellow, which has a molecular weight of $443 \mathrm{Da}$ and carries a charge of -2 . After the intracellular injection of Lucifer yellow, a dye-coupled network of A-type $\mathrm{HCs}$ is recovered in which the somas and thick primary dendrites are particularly prominent (Fig. 1A) (Dacheux and Raviola, 1982; Mills and Massey, 1994). There is a substantial intensity gradient from the injection site to the edge of the figure which reflects the relatively low permeability of Lucifer yellow. Neurobiotin $(286 \mathrm{Da} ;+1)$ was simultaneously injected through the same pipette, and when visualized with streptavidin/Cy3, a much larger patch of A-type HCs is visible (Fig. $1 B$ ). In Figure $1 C$, all of the cells are double labeled with the central cells yellow fading to orange in the periphery because of the relatively poor diffusion of Lucifer yellow.

In contrast, filling B-type HCs with the two dyes yielded a different result. In B-type HCs, Lucifer yellow labeled only the injected cell and did not pass through the network (Fig. 1D). Nevertheless, B-type HCs are coupled as demonstrated by the injection of Neurobiotin, which labeled an extensive patch of coupled cells (Fig. $1 E$ ). In Figure $1 F$, there is only one central double-labeled B-type HC surrounded by a patch of Neurobiotin-coupled cells. This is a direct demonstration that A-type and B-type HCs have different dye coupling properties, as reported previously (Mills and Massey, 1994, 1998). This immediately suggests the presence of different gap junction proteins in the two types of horizontal cell.

\section{Identification of connexins in rabbit retina}

Many studies indicate that $\mathrm{Cx} 36$ is an important connexin in retinal neurons (Sohl et al., 1998; Feigenspan et al., 2001; Mills et al., 2001; Deans et al., 2002). However, coupling in some well coupled neurons, such as horizontal cells, cannot be attributed to Cx36. Cx40 has been reported to be present in bovine and rat retina (Matesic et al., 2003) based on immunostaining with a 


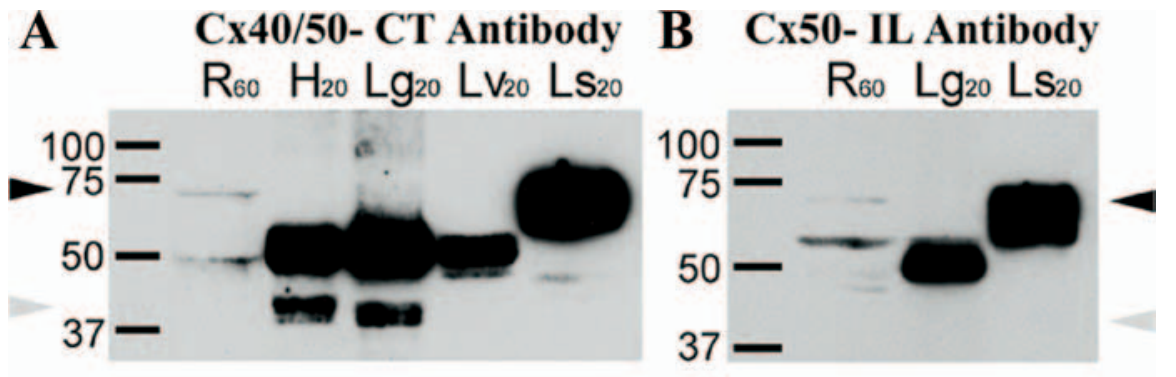

C

Rabbit Retina Connexin50

(5') ATGGGCGACTGGAGTTTCCTGGGGAACATCTTGGAGGAGGTGAATGAGCACTCCACAGTCATCGG CAGGGTCTGGCTCACCGTGCTTTTCATCTTCCGCATCCTGATTCTCGGCACAGCCGCAGAGTTCGTGTG GGGGGATGAGCAGTCCGACTTCGTGTGCAATACCCAGCAGCCCGGTTGCGAGAATGTCTGCTACGATGA GGCTTTCCCCATCTCCCACATCCGCCTGTGGGTCCTGCAGATCATCTTCGTCTCCACACCGTCCCTCAT GTACGTGGGCCATGCCGTGCACCACGTGCGCATGGAGGAGAAGCGCAAGGACCGCGAGGCGGAGGAGCT GTGCCAGCAGTCCCGGGGCGACGGGAGCGAGAGGGTGCCCATCAGCCCCGACCAGGGCAGCATCAGGAA GAGCAGCAGCAGCAGCAAAGGCACCAAGAAGTTCCGGCTGGAGGGGACTCTGCTGAGGACCTACATCTG CCACATCATCTTCAAGACCCTCTTTGAGGTGGGCTTCATTGTGGGCCACTACTTCCTGTATGGTTTCCG GATCCTGCCCCTCTACCGCTGCAGCCGCTGGCCCTGCCCCAATGTGGTGGACTGCTTCGTGTCCCGACC CACTGAGAAAACCATCTTCATCTTGTTCATGTTGTCTGTGGCCTTTGTGTCGCTCTTCCTCAACATTAT GGAGCTGAGCCACCTGGGCCTGAAGGGGATCCGGTCTGCCTTCAAGAGGCCTGTCGAGCAGCCCCTCGG GGAGATCCCTGAGAAATCCCTCCACTCCATTGCCGTCTCTTCCATCCAGAAAGCGAAGGGCTACCAGCT CCTTGAAGAAGAGAAGATCGTGTCCCACTACTTCCCATTGACTGAGGTTGGGATGGTGGAGACCAGCCC CCTGTCTGCCAAGCCTTTCAGTCAGTTCGAGGAAAAGATCAGCACTGGACCCCTAGCGGACATGCCCCG GAGTTACCAAGAGACACTGCCTTCCTATGCCCAGGTGGGCGCACCGGAAGTGGAAGGGGAGGAGCCGCC AGTAGAGGAGGCCGCAGAACCGGAAGTGGGAGAGAAGAGGCCGGAAGCTGAGAAGGTGACCGCAGAAGG GCCAGAGATGGTGGCTGTGCTGGAGGCGGAGAAAATAGAGCCCCCTGCTGTGGGGAAGGAAGGAGAAAA GGAGGAGCTGCAGGCTGAGGTTGCCAAGCAAGGGCTGGCGGCTGAGAAGACGCCTCCGCTGTGTCCGGA GCTGACCTCCGAAGATACCAGACCTCTGAGCAGGCTGAGCAAAGCCAGCAGCAGAGCCAGGTCAGACGA TCTAACCGTATGA ( $\left.3^{\prime}\right)$

MGDWSFLGNILEEVNEHSTVIGRVWLTVLFIFRILILGTAAEFVWGDEQSDFVCNTQQPGCENVCYDEA FPISHIRLWVLQI IFVSTPSLMYVGHAVHHVRMEEKRKDREAEELCQQSRGDGSERVPISPDQGSIRKS SSSSKGTKKFRLEGTLLRTYICHI IFKTLFEVGFIVGHYFLYGFRILPLYRCSRWPCPNVVDCFVSRPT EKTIFILFMLSVAFVSLFLNIMELSHLGLKGIRSAFKRPVEQPLGEIPEKSLHSIAVSSIQKAKGYQLL EEEKIVSHYFPLTEVGMVETSPLSAKPFSQFEEKISTGPLADMPRSYQETLPSYAQVGAPEVEGEEPPV EEAAEPEVGEKRPEAEKVTAEGPEMVAVLEAEKIEPPAVGKEGEKEELQAEVAKQGLAAEKTPPLCPEL TSEDTRPLSRLSKASSRARSDDLTV

Figure 2. Western blot analysis of $\mathrm{C} \times 50$ antibodies and $\mathrm{C} \times 50$ sequence. $A, \mathrm{C} \times 40 / \mathrm{C} \times 50-\mathrm{CT}$ antibody. Lane 1, Molecular weight markers; lane 2, retina; lane 3, heart; lane 4, lung; lane 5, liver; lane 6, lens. The Cx40/Cx50-CT antibody recognized (X40 from heart and lung (gray arrowhead; $\sim 40 \mathrm{kDa}$ ). This band was not present in retina or lens. Instead, this antibody recognized a band close to $70 \mathrm{kDa}$ in retina and lens (black arrowhead). This band was absent in heart, lung, and liver. (x50 has been identified as MP70, one of the major intrinsic proteins of the lens with an apparent molecular mass of $70 \mathrm{kDa}$ (White et al., 1992). In addition, a nonspecific protein was stained in all tissues at $\sim 50 \mathrm{kDa}$, perhaps denatured rabbit Ig G heavy chains. B, Cx50-IL antibody. Lane 1 , Molecular weight markers; lane 2, retina; lane 3, lung; lane 4, lens. The (x50-IL antibody also recognized a band close to $70 \mathrm{kDa}$ in retina and lens (black arrowhead). This antibody did not produce a $40 \mathrm{kDa}$ band (gray arrowhead) in retina or in lung, which is a control tissue for $\mathrm{C} \times 40$. As before, a nonspecific band at $\sim 50 \mathrm{kDa}$ was also stained. In summary, these blots demonstrate that the Cx50-CT and the $\mathrm{Cx} 50-\mathrm{IL}$ antibodies both recognize a $70 \mathrm{kDa}$ band in retina, which is equivalent to MP70 or Cx50 from lens. Because Cx40 is absent from retina, the $\mathrm{Cx} 50-\mathrm{CT}$ antibody can be used to label $\mathrm{Cx} 50$ gap junctions in retina. $C$, Rabbit $C \times 50$ nucleotide and amino acid sequences. $\mathrm{C} \times 50$ cDNA was isolated from rabbit retina. Rabbit $\mathrm{C} \times 50$ is a 1320 bp sequence that encodes a 440 aa protein, which is 80.1 and $83.4 \%$ similar to human and mouse, respectively. Overall, the rabbit $C \times 50$ and rabbit Cx40 sequences are very similar (71\%). When the C-terminal portion of rabbit $\mathrm{C} \times 50$ was sequenced, C-terminal amino acids $425-440$ were highly similar (87\%) to rabbit Cx40 C-terminal amino acids 343-358, the region used to raise an antibody. The regions for the intracellular loop (I-loop) peptide and the C-terminal peptide are marked by underlining.

commercial antibody against a Cx40 C-terminal peptide (amino acids 340-358). We examined whether this antibody recognized connexins in Western blots of rabbit tissues. Cx40 occurs in heart and lung tissues, and antibodies against $\mathrm{Cx} 40$ label a band in Western blots that is near the predicted molecular weight (40 kDa) (Beyer et al., 1992; Hennemann et al., 1992; Gros et al., 1994; Kanter et al., 1994). The Cx40 C-terminal antibody recognized this band in heart and lung tissues from rabbit (Fig. $2 \mathrm{~A}$ ) but did not recognize a comparable band in rabbit retina. A nonspecific band of $\sim 50 \mathrm{kDa}$ was detected in all three tissues. In addition, the $\mathrm{Cx} 40$ antibody labeled a band of $\sim 70$
$\mathrm{kDa}$ in rabbit retina (Fig. $2 A$, lane 1 ). The Cx40 antibody also recognized a dense band of $\sim 70 \mathrm{kDa}$ in rabbit lens (Fig. 2A, lane 5).

Mammalian lens is known to express Cx43, Cx46, and Cx50 (White et al., 1992). Cx50 has been identified as membrane protein 70 (MP70), one of the major intrinsic proteins of the lens with an apparent molecular mass of $70 \mathrm{kDa}$ (White et al., 1992). We hypothesized that the 70 $\mathrm{kDa}$ band recognized by the Cx40 antibody in rabbit retina and rabbit lens may be Cx50. We note that amino acids 425440 from the C-terminal of rabbit Cx50 are highly similar $(87 \%)$ to amino acids 343-358 from the C-terminal of rabbit Cx40. To test this hypothesis, we performed Western blots with another specific antibody against the intracellular loop of Cx50 (Cx50-IL) (White et al., 1992). Figure $2 B$ shows that this antibody also recognized the same $70 \mathrm{kDa}$ band in rabbit retina as well as the high molecular weight band (MP70) in rabbit lens. This indicates that $\mathrm{Cx} 50$ is expressed in rabbit retina, and the $\mathrm{Cx} 40$ antibody from Chemicon also recognizes the C-terminal of rabbit $\mathrm{Cx} 50$. Therefore, throughout the rest of the paper, this antibody will be referred to as Cx50-CT.

To examine whether $\mathrm{Cx} 50$ is expressed in retina, we performed RT-PCR on rabbit retina total RNA with $\mathrm{Cx} 50$-specific primers. This resulted in amplification of several fragments of Cx50 cDNA. We subsequently used 3 '-rapid amplification of cDNA ends to amplify the C-terminal portion of $\mathrm{Cx} 50$ to yield the full coding region of Cx50 (Fig. 2C). The coding region of rabbit Cx50 was 1320 bp and encoded a 440 aa protein. Rabbit Cx50 was $80.1 \%$ similar to human Cx50 and $83.4 \%$ similar to mouse $\mathrm{Cx} 50$ at the amino acid level.

Because the connexin responsible for the densely coupled network of A-type horizontal network was unknown (Deans and Paul, 2001; Mills et al., 2001), we examined isolated A-type HCs to see whether they expressed Cx50 mRNA. Rabbit retina was dissociated, and A-type HCs were easily identified based on their morphology (Fig. 3A). We collected single A-type HCs with a suction pipette and isolated RNA for single cell RT-PCR. As a positive control, $\beta$-actin was amplified from dissociated cells by RT-PCR. On the $\beta$-actinpositive samples, primers specific for $\mathrm{Cx} 50$, Cx40, and metabotropic glutamate receptor 6 (mGluR6) were used in RT-PCR. Eighteen of $20 \beta$-actin-positive cells were positive for Cx50, but all were negative for $\mathrm{Cx} 40$ and mGluR6. Examples of RT-PCR from a few A-type HCs are shown in Figure $3 B$. These experiments indicate that $\mathrm{Cx} 50$ is expressed by rabbit A-type horizontal cells. 
A

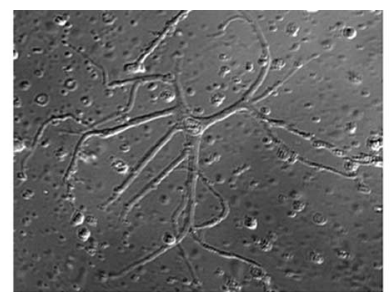

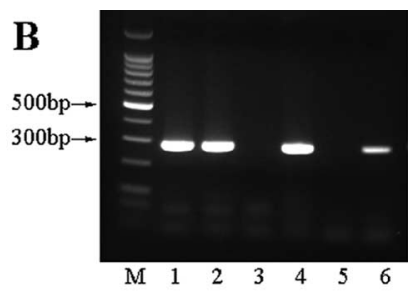

Figure 3. Single-cell RT-PCR and Western blot analyses show $C x 50$ is expressed in rabbit A-type horizontal cells. A, Dissociated A-type HCs from dissociated rabbit retina were identified based on their characteristic morphology and collected for single-cell RT-PCR with a suction pipette. $\boldsymbol{B}$, Single-cell RT-PCR shows that $\mathrm{C} \times 50$ is expressed in A-type HCs of the rabbit retina. M, The 100 bp molecular weight standard. Lanes 1-4 show different individual A-type HCs; lane 5 shows no DNA negative control; lane 6 shows positive control with rabbit retina CDNA. The expected size of the product is $284 \mathrm{bp}$. Thus, these experiments indicate that $\mathrm{C} x 50$ is expressed by isolated rabbit A-type HCs.

\section{A-type horizontal cells express connexin $\mathbf{5 0}$}

A-type HCs in the rabbit retina can be labeled conveniently with antibodies against calbindin (Rohrenbeck et al., 1987). A few other structures, such as B-type somas and certain bipolar cells are also lightly labeled, but the most prominent structure is the matrix of A-type HCs (Massey and Mills, 1996). The two different Cx50 antibodies, against the intracellular loop (I-loop) or C terminus, were used in double label experiments with essentially the same result (Fig. 4). Cx50 labeling is confined to the A-type HCs, and both antibodies revealed similar labeling patterns. Where large primary dendrites cross, there are often giant $\mathrm{Cx} 50$ plaques with irregular or polygonal shapes. When the horizontal cell dendrites run parallel together, long strings of Cx50 labeling occur, particularly in superior retina where the A-type HCs tend to be elongated. In addition, there were many small $\mathrm{Cx} 50$ clusters along the finer dendrites of the A-type HCs, which may be very lightly stained for calbindin. A more detailed view was obtained after filling with Neurobiotin (see below), but to a close approximation, all the Cx50 immunoreactivity was confined to the matrix of horizontal cells. We have learned that this pattern of labeling, at dendritic crossings and intersections, is diagnostic for gap junction labeling (Mills et al., 2001).

The Cx50 C-terminal antibody appears to have a higher affinity and provides brighter labeling with more detail compared with the Cx50 I-loop antibody. The Cx50 C-terminal antibody also produces faint and diffuse speckled labeling of the outline of the A-type HCs, which is not present in other neurons (Fig. 4D). Because it is restricted to the outline of A-type HCs, this labeling may represent the trafficking of $\mathrm{Cx} 50$ hemichannels in the cell membrane as they diffuse to form $\mathrm{Cx} 50$ plaques. We differentiate between the diffuse labeling, which outlines major dendrites but contains no clusters large enough to resolve, and Cx50 plaques, which are bright, demarcated and form gap junctions at the contact points between overlapping A-type HCs.

A giant Cx50 plaque, $\sim 7 \mu \mathrm{m}$ in diameter $\left(20.1 \mu \mathrm{m}^{2}\right)$, is shown at a high magnification in Figure $4 E$. The plaque occurs at the intersection of two primary A-type HC dendrites and fills the entire region of the dendritic crossover. A through-focus image series indicates that the gap junction plaque lies at the interface between the two dendrites. There are "holes" in the central region of the plaque, a feature common to large plaques in both inferior and superior retina. It should be noted that the holes go right through the gap junction, and they do not represent undersampled folds or 3D structure. Furthermore, this substructure is found with both Cx50 antibodies and it may be a result of connexin turnover. New connexons are added to the edge of the plaque, and old connexins are removed from the center (Lauf et al., 2002).

To confirm the specificity of the Cx50 antibodies, both were used in a double label experiment. Because the $\mathrm{C}$ terminus of Cx50 is cleaved in the lens (White et al., 1992; Lin et al., 1997, 1998), it was possible that cleaved forms of Cx50 would not be recognized by an antibody developed against the $\mathrm{C}$ terminus. These modified forms of $\mathrm{Cx} 50$, however, would be recognized by the antibody against the intracellular loop of Cx50 (White et al., 1992).

Because the antibodies were both raised in rabbits, we followed a sequential procedure so that one primary antibody was developed with the first secondary ( $\mathrm{Cy} 3$ ) followed by a blocking step before the next primary was applied and visualized with another secondary antibody of a different color (Alexa 488). With this sequence, only the first primary antibody is exposed to Cy3, but the Alexa 488 secondary can label both primaries. Figure 5 shows a typical result. The first Cx50 antibody against the intracellular loop stained the A-type $\mathrm{HC}$ matrix at dendritic crossings and areas of contact as above. The second Cx50 antibody stained exactly the same structures. Of course, this is ambiguous because the gap junctions could either be labeled with both primary antibodies or the first antibody alone could be recognized by both secondaries. However, the second Cx50 antibody labeled no additional structures, and the same result was obtained if the order of the primary antibodies was reversed. Thus, despite the limitations of the sequential application, it appears that both antibodies recognize the same structures. Recognition of the same target by antibodies against two different regions of the same protein is strong evidence for antibody specificity and the presence of Cx50 in the A-type HC matrix. Additionally, because the substructure was still present in the large plaques using both antibodies, we believe that the holes in large Cx50 gap junctions result from plaque remodeling rather than from Cx50 cleavage (Lauf et al., 2002; Zampighi et al., 2005).

\section{Size analysis}

To determine the distribution of Cx50 plaques and the relative contribution of giant plaques, a size analysis was conducted. A threshold intensity of 60 was applied to remove background signals and puncta smaller than $0.1 \mu \mathrm{m}^{2}$, approximately the resolution limit of the microscope, were excluded. These signals fall into at least three groups that could not be discriminated: (1) a fine background noise randomly distributed throughout the images; (2) a fine diffuse label dispersed throughout the major horizontal cell dendrites, which may represent hemichannel trafficking before incorporation into a gap junction; this diffuse labeling contained no resolvable plaques; (3) some extremely small gap junction clusters close to the detection limit.

The size analysis showed several trends (Table 1, Fig. 6). First, Cx50 plaques displayed a wide variety of shapes and sizes, which ranged from $0.1 \mu \mathrm{m}^{2}$ puncta to giant plaques larger than 100 $\mu \mathrm{m}^{2}$. The Cx50 plaques in whole-mount rabbit retina had an average of $0.55 \pm 0.82 \mu \mathrm{m}^{2}$. Second, in central retina, small gap junctions were predominant, both numerically $(86 \%)$ and in their contributions to the total area (44\%). In peripheral retina, small gap junctions were still numerous $(66 \%)$, but they only accounted for $22 \%$ of the total area, as opposed to $44 \%$ for medium Cx50 clusters $\left(1-5 \mu \mathrm{m}^{2}\right)$. Many small gap junctions occurred where fine horizontal cell dendrites crossed beneath the cone pedicles (see below). Third, the large gap junction structures $\left(>5 \mu \mathrm{m}^{2}\right)$ occurred more often in peripheral retina where they accounted for $\sim 5 \%$ of gap junctions, compared with $<1 \%$ in central retina. Thus, peripheral gap junctions tend to be larger. 

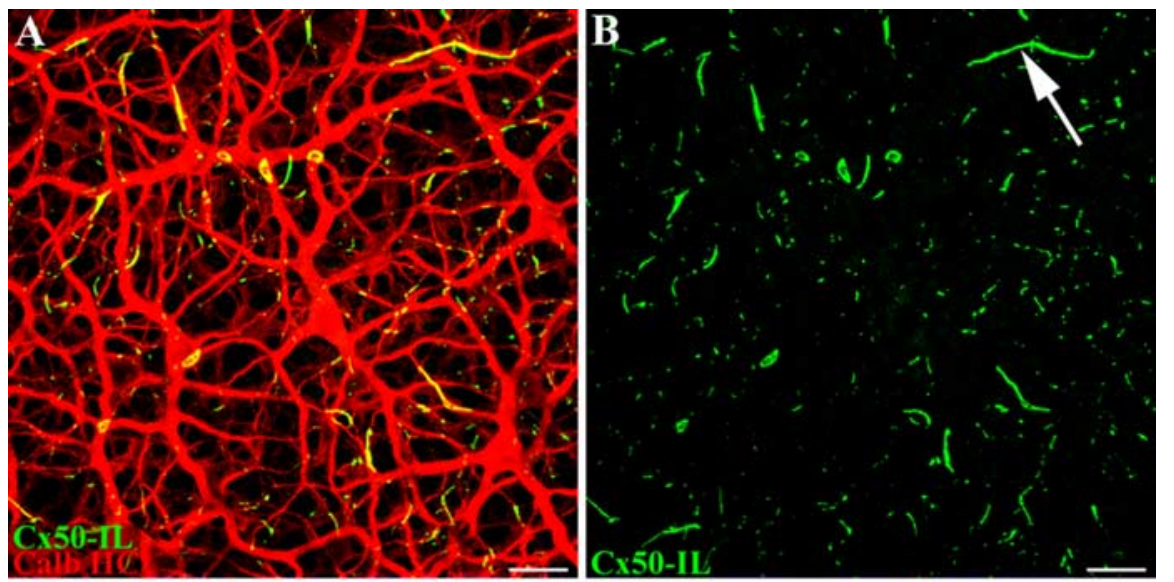

"strings" between adjacent dendrites, whereas round or oval structures were more common in inferior retina.

At $1 \mathrm{~mm}$ below the visual streak $(\sim 3.6$ $\mathrm{mm}$ inferior to the myelinated band), we estimated that the Cx50 plaques covered a total area of at least $4.1 \times 10^{4} \mathrm{\mu m}^{2} / \mathrm{mm}^{2}$ (Fig. $6 \mathrm{~B}$ ). Dividing by the local density of A-type HCs at this eccentricity (365/ $\mathrm{mm}^{2}$ ) (Mills and Massey, 1994), we estimate that there is $\sim 112 \mu \mathrm{m}^{2}$ of Cx50 gap junction per A-type HC. Additionally, at 1 $\mathrm{mm}$ from the visual streak, the largest Cx50 plaque covered $52.3 \mu \mathrm{m}^{2}$. In this region, there were 213 gap junction plaques per A-type HC. As we have seen, giant
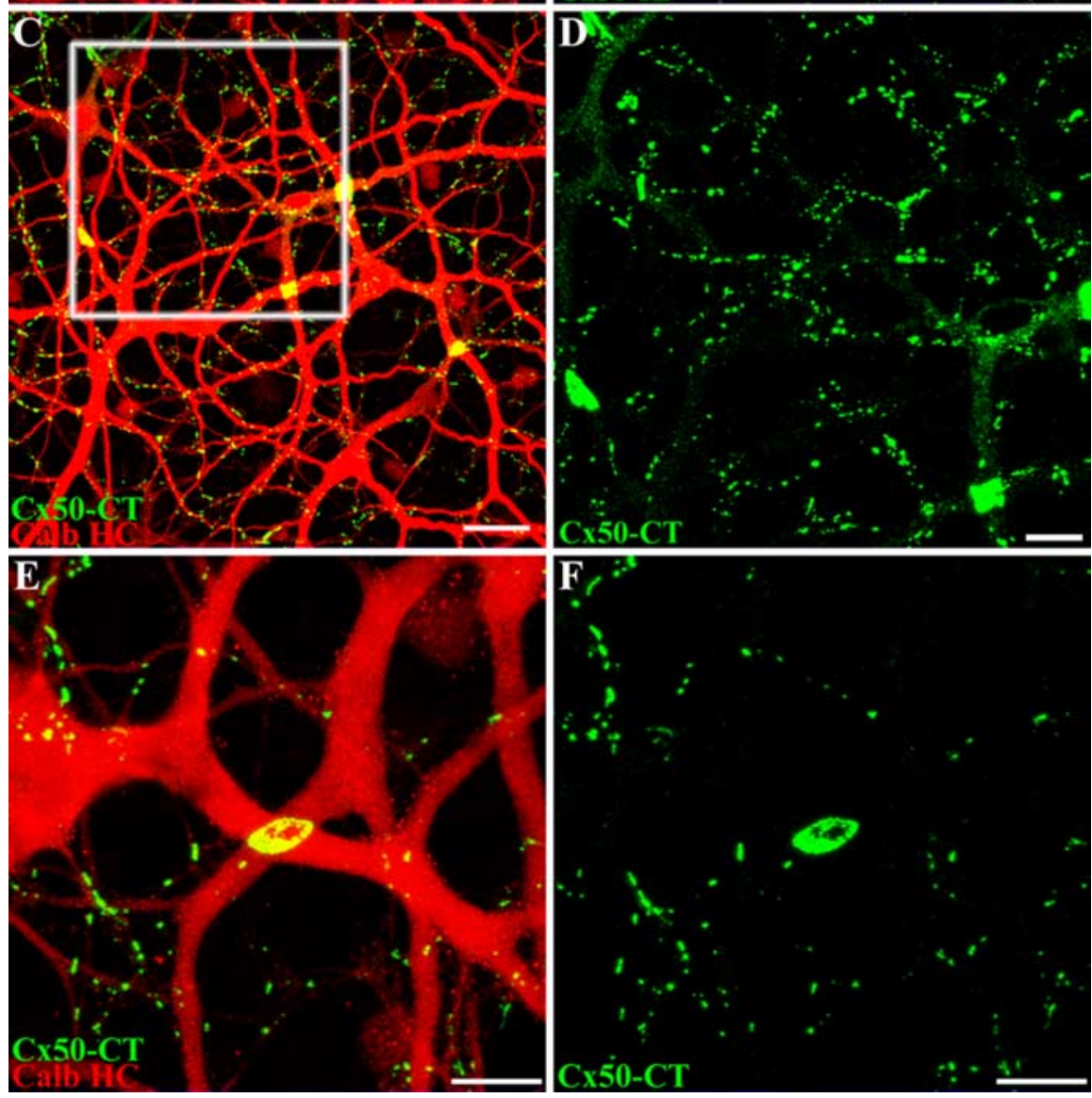
plaques often have central holes. However, the holes were not included in the size analysis because only contiguous pixels in the gap junction plaque were selected. The connexin area per tissue area increased slightly from the central to peripheral retina. As the horizontal cell density decreased from central to peripheral retina, the connexin area per horizontal cell increased from 75 to 244 $\mu \mathrm{m}^{2}$ per HC cell (Fig. $6 B$ ). This mirrors the increase of $\sim 3$ in dendritic field area from central to peripheral retina, the reciprocal of the fall in cell density, as required to maintain an even coverage across the retina (Mills and Massey, 1994). Thus, the number of gap junctions per unit area of horizontal dendritic field appears to be invariant across the retina.

\section{Connexin 50 is located on horizontal} cell dendrites beneath the cone pedicle In the above experiments, when calbindin was used as a marker for A-type HCs, we noticed that small Cx50 clusters were often found at the terminal dendrites, in the vicinity of cone pedicles. Because it is difficult to visualize the fine dendrites of horizontal cells in material labeled for calbindin, we chose to fill A-type HCs with Neurobiotin. In fact, the extensive cou-

Figure 4. Cx50 plaques occur at dendritic crossings in calbindin-labeled A-type horizontal cells. A-D, Whole-mount rabbit retina labeled with calbindin antibody (red) and antibodies that recognized different regions of $C \times 50$, either $C \times 50-\mathrm{IL}(A, B)$ or $\mathrm{Cx} 50-\mathrm{CT}(\boldsymbol{C}-\boldsymbol{F})$ (green). Both $\mathrm{Cx} 50$ antibodies produced the same results. Many small $\mathrm{C} \times 50$ plaques occur along the fine $\mathrm{A}$-type $\mathrm{HC}$ dendrites, but most notably, giant $\mathrm{C} \times 50$ plaques appear at the dendritic crossings of A-type $\mathrm{HC}$ primary dendrites. $A, B$, Long $C \times 50$ "strings" occur more often in superior retina where A-type $\mathrm{HC}$ dendrites run parallel (arrow). $C$, Inferior retina shows very prominent giant $C \times 50$ plaques. $D$, An enlarged field from the box in $C$ shows the $C \times 50$ labeling alone. Faint diffuse staining occurs along some of the primary dendrites, which may represent hemichannel trafficking. Scale bars: $A, B, 20 \mu \mathrm{m} ; \boldsymbol{C}, 25 \mu \mathrm{m} ; \boldsymbol{D}, 10 \mu \mathrm{m} . \boldsymbol{E}, \boldsymbol{F}$, A high-magnification image shows that small $\mathrm{C} x 50$ plaques occur on the intersections of fine A-type $\mathrm{HC}$ dendrites. [Some fine dendrites are not visible after staining with the calbindin antibody (see Results and Fig. 7).] In addition, a large Cx50 plaque, 7.3 $\mu \mathrm{m}$ in diameter $\left(20.1 \mu \mathrm{m}^{2}\right)$, occurs at the intersection of two primary A-type HC dendrites. The "holes" within the Cx50 plaque may result from connexin turnover. Scale bars: $\boldsymbol{E}, \boldsymbol{F}, 10 \mu \mathrm{m}$.

pling between A-type HCs results in a relatively poor fill from a single tracer injection, because the Neurobiotin diffuses away through the major dendrites of the horizontal cell matrix. This problem was overcome by injecting a ring of three or four A-type HCs to get more dye into the matrix. Under these conditions, large sections of the A-type HC matrix were completely filled so that even the finest terminal dendrites were labeled (Fig. 7).

Giant Cx50 plaques occurred where large, primary dendrites crossed. The largest Cx50 plaque in this analysis was $113 \mu \mathrm{m}^{2}$ with significant substructure present within the plaque. In fact, the giant Cx50 plaque in Figure 8 is $63 \mu \mathrm{m}^{2}$. Fourth, in superior retina, the largest gap junctions occurred as long linear rows or
A low-power view (Fig. 7A) shows the A-type HC matrix filled with Neurobiotin. The major dendrites are prominent, as with the calbindin antibody, but in addition, many fine dendrites and the terminal clusters, which indicate the sites of cone pedicles, are also labeled. It should be noted that essentially all of the Cx50 

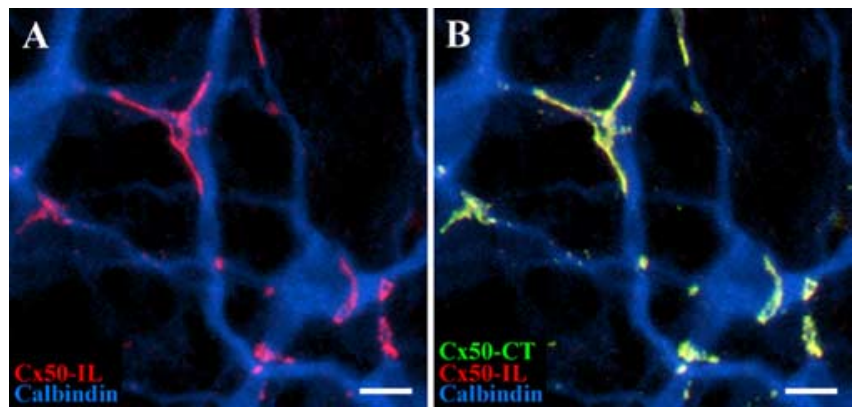

Figure 5. Antibodies against $\mathrm{C} \times 50-\mathrm{IL}$ and $\mathrm{C} \times 50-\mathrm{CT}$ label the same structures on A-type horizontal cells. Sequential labeling with Cx50-IL and Cx50-CT antibodies. A, The Cx50-IL antibody (red) labeled gap junction plaques on the calbindin-labeled matrix of A-type HCs (blue). $\boldsymbol{B}$, In the same piece of retina, sequential labeling with Cx50-CT antibodies (green) marked the same structures with no additional labeling. The overlap from the two $\mathrm{Cx} 50$ antibodies (red plus green) produces yellow labeling. The same result was obtained if the sequence of Cx50 antibodies was reversed. Scale bars, $10 \mu \mathrm{m}$.

labeling is found on the A-type HC matrix when it is completely filled in this way with Neurobiotin. This suggests that only A-type HCs express Cx50. The large plaques occur at the intersections of major dendrites but many small $\mathrm{Cx} 50$ profiles are found along small branches, particularly where they cross major dendrites. A high-magnification view shows that several fine dendrites converge to form a terminal cluster (Fig. $7 B$ ). Several small Cx50 profiles seem to occur between horizontal cell dendrites beneath the cone pedicle.

There are few selective markers to label the cone pedicles. However, certain OFF cone bipolar cells express kainate receptors on their dendritic processes and they may be labeled with an antibody against GluR5 (Haverkamp et al., 2001, 2003; Li and DeVries, 2004). This procedure effectively marks the sites of the cone pedicles (Fig. 8A). As expected, the terminal clusters of A-type HCs are found at every cone pedicle where the horizontal cell processes are intermingled with the dendrites of OFF cone bipolar cells. Giant Cx50 gap junctions are found on major dendrites without regard to the cone mosaic. This is particularly obvious for the giant plaque in Figure $8 A$, which has an area of 63 $\mu \mathrm{m}^{2}$ and typical holes in the central region. In addition, many small Cx50 plaques occur at or close to the cone pedicles. However, this is not a requirement, because some cone pedicles, marked by the presence of GluR5, have little or no Cx50 labeling (Fig. $8 \mathrm{~A}$ ). At high magnification, it can be seen that several horizontal cell processes converge at a single cone pedicle (Fig. $8 \mathrm{~B}$ ). The GluR5 and the Neurobiotin labeling are not colocalized. This is because they label two different types of neurons, OFF cone bipolar cells and A-type HCs, which both converge at the cone pedicle mosaic. There are several small Cx50 plaques close to the site of the cone pedicle (Fig. $8 C$ ). The Cx50 plaques occur exclusively on the A-type $\mathrm{HC}$ dendrites where they branch and meet beneath the cone pedicle (Fig. $8 D$ ).

\section{Two dye injections}

When the A-type HC matrix is uniformly filled with Neurobiotin, it can be seen that Cx50 is confined to A-type HCs. However, it is frequently difficult to tell whether the gap junctions occur between two different cells or in isolation, especially along the finer dendrites. Specifically, because gap junction proteins migrate and dock to form gap junction plaques at the contact point between two cells, we expect to find Cx50 plaques where two cells are in close apposition. The complexity and overlap within the matrix makes it necessary to label different horizontal cells with distinct markers so they can be clearly distinguished. This was achieved by filling single A-type HCs with Alexa 568 hydrazide in a patch of matrix previously labeled with Neurobiotin in the usual way. In Figure 9, a single A-type HC is labeled with both Neurobiotin and Alexa 568, and it is shown in purple (blue plus red) against a background of cells filled with Neurobiotin only (blue).

In Figure 9C, a string of small Cx50 plaques occurs between two A-type HC dendrites that run closely parallel. There are multiple gap junctions along the length of the adjoining dendrites. This would have been almost impossible to see without differentially labeling the horizontal cell processes. At terminal clusters, beneath the cone pedicle, it is clear that both blue and purple processes converge. Furthermore, at some terminal clusters, it appears that the Cx50 plaques occur at contact points between the dendrites of differentially labeled horizontal cells. It is also possible that some Cx50 plaques could occur between dendrites arising from the same HC. In the cluster circled in Figure 9D, there are three small Cx50 plaques and they all occur where the blue and purple dendrites are mingled. In summary, the two dye injections demonstrate that $\mathrm{Cx} 50$ gap junctions are found at the contact points between different A-type HCs. This is the expected location for a horizontal cell gap junction. We were unable to detect $\mathrm{Cx} 50$ on isolated dendrites, which suggests either there were no unapposed hemichannel aggregates or they were below the detection threshold.

\section{B-type horizontal cells do not express Cx50}

The rabbit retina contains B-type HCs as well as A-type HCs. However, B-type HCs have different dye coupling properties (Vaney, 1993; Mills and Massey, 1994, 2000). This immediately suggests the presence of distinct connexins in each horizontal cell type. Therefore, we examined the expression of Cx50 in B-type HCs.

In a triple-label experiment, a single B-type $\mathrm{HC}$ was dye injected with Neurobiotin (red), producing a small patch of coupled cells with an overlapping matrix of dendrites (Fig. 10A). $\mathrm{B}$-type $\mathrm{HCs}$ have more radial dendrites, and many dendritic crossings between neighboring cells are present in this field. $\mathrm{Nu}$ merous Cx50 plaques (green) are present in this frame but they are not colocalized with the dendrites of B-type HCs. Specifically, Cx50 plaques do not occur at dendritic crossings in the B-type HC matrix.

The outer plexiform layer is actually somewhat stratified in that the major dendrites of A-type HCs are adjacent to the inner nuclear layer, whereas the finer B-type processes tend to lie a little higher, toward the cone pedicles. Thus, to obtain a complete view of the A-type HCs, the injected B-type $\mathrm{HC}$, and the $\mathrm{Cx} 50$ plaques, it was necessary to present a projected stack of images. To visualize A- and B-type HCs from the somas in the inner nuclear layer through to the terminal dendrites, this image was reconstructed through the entire outer plexiform layer $(\mathrm{OPL})(37 \times 0.3 \mu \mathrm{m}$; $11.1 \mu \mathrm{m})$. This also has the advantage of flattening ripples in the tissue. However, because this image is a confocal stack, occasionally there was coincidental overlap between the Cx50 labeling and the B-type HCs. In these examples, animating through the stacked images showed that Cx50 labeling was always at a different depth in an A-type process.

In the same field, the A-type HC matrix was labeled with an antibody against calbindin (blue) (Fig. 10B) and the Cx50 plaques were labeled with a C-terminal antibody (green). As before, it is immediately obvious that Cx50 plaques are almost entirely restricted to the matrix of A-type HCs. Thus, the Cx50 plaques appear cyan (green plus blue) because they are colocal- 
Table 1. Size analysis of $\mathrm{C} \times 50$ gap junctions in rabbit retina

\begin{tabular}{|c|c|c|c|c|c|c|c|}
\hline & $\begin{array}{l}\text { Very small puncta } \\
\left(0.1-1 \mu \mathrm{m}^{2}\right)\end{array}$ & $\begin{array}{l}\text { Small clusters } \\
\left(1-5 \mu \mathrm{m}^{2}\right)\end{array}$ & $\begin{array}{l}\text { Large clusters } \\
\left(5-10 \mu \mathrm{m}^{2}\right)\end{array}$ & $\begin{array}{l}\text { Very large plaques } \\
\left(10-20 \mu \mathrm{m}^{2}\right)\end{array}$ & $\begin{array}{l}\text { Extra large plaques } \\
\left(20-40 \mu \mathrm{m}^{2}\right)\end{array}$ & $\begin{array}{l}\text { Giant plaques } \\
\left(>40+\mu \mathrm{m}^{2}\right)\end{array}$ & $\begin{array}{l}\text { Largest plaque } \\
\left(\mu \mathrm{m}^{2}\right)\end{array}$ \\
\hline \multicolumn{8}{|l|}{ Central retina } \\
\hline Area (mean $\pm S D$ ) & $0.32 \pm 0.22$ & $1.83 \pm 0.85$ & $6.86 \pm 1.41$ & $13.9 \pm 2.60$ & $30.3 \pm 5.86$ & $46.9 \pm 4.95$ & 52.2 \\
\hline Fraction of total number & $86.9 \%$ & $12.3 \%$ & $0.58 \%$ & $0.16 \%$ & $0.04 \%$ & $0.01 \%$ & \\
\hline Fraction of total area & $47.9 \%$ & $38.5 \%$ & $6.79 \%$ & $3.71 \%$ & $2.22 \%$ & $0.93 \%$ & \\
\hline \multicolumn{8}{|l|}{ Superior retina } \\
\hline Area (mean $\pm S D$ ) & $0.35 \pm 0.24$ & $2.05 \pm 0.96$ & $6.87 \pm 1.31$ & $13.8 \pm 2.93$ & $25.3 \pm 4.47$ & $41.0 \pm 0.00$ & 41.0 \\
\hline Fraction of total number & $72.0 \%$ & $23.8 \%$ & $3.02 \%$ & $0.97 \%$ & $0.20 \%$ & $0.01 \%$ & \\
\hline Fraction of total area & $22.3 \%$ & $43.0 \%$ & $18.2 \%$ & $11.7 \%$ & $4.47 \%$ & $0.34 \%$ & \\
\hline \multicolumn{8}{|l|}{ Inferior retina } \\
\hline Area (mean $\pm S D)$ & $0.37 \pm 0.24$ & $2.05 \pm 0.96$ & $6.79 \pm 1.35$ & $13.1 \pm 2.43$ & $26.2 \pm 5.04$ & $42.3 \pm 2.94$ & 113 \\
\hline Fraction of total number & $71.4 \%$ & $25.1 \%$ & $2.49 \%$ & $0.78 \%$ & $0.18 \%$ & $0.06 \%$ & \\
\hline Fraction of total area & $22.8 \%$ & $44.6 \%$ & $14.7 \%$ & $8.85 \%$ & $4.16 \%$ & $2.10 \%$ & \\
\hline
\end{tabular}

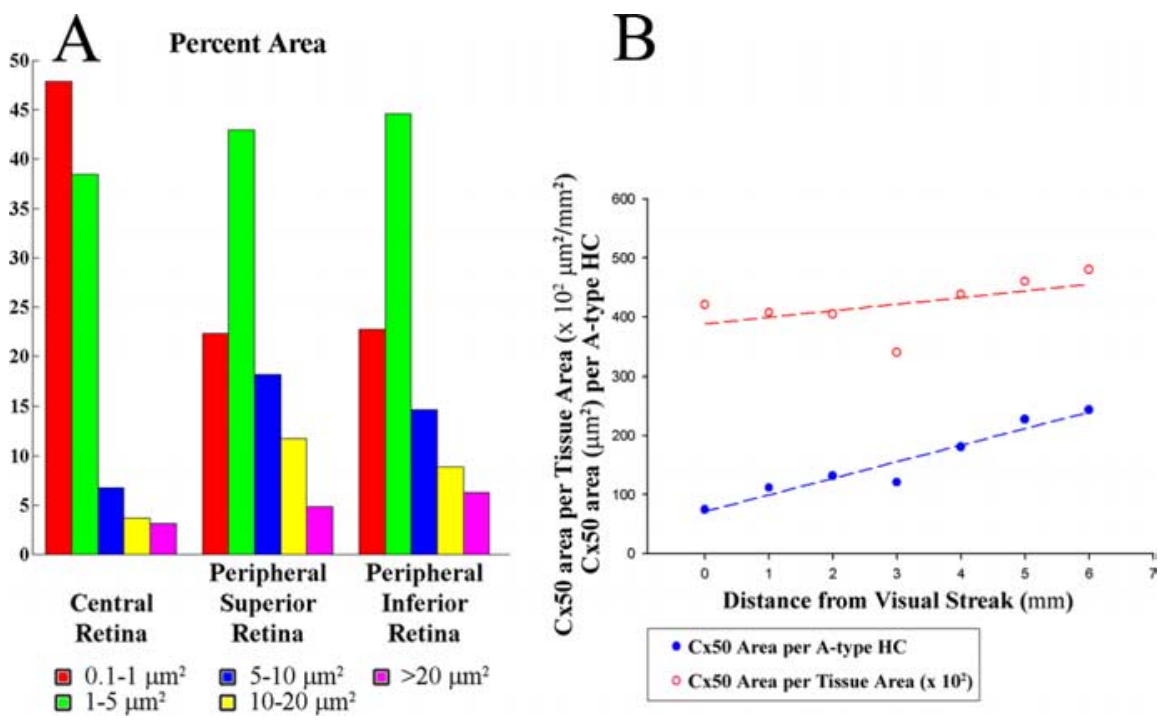

Figure 6. Cx50 plaque area increases from central to peripheral retina. $A$, In central retina, the extra small puncta $\left(0.1-1 \mu \mathrm{m}^{2}\right)$ accounted for both the largest percentage and area covered ( 85.7 and $44.4 \%$, respectively). Conversely, large $C \times 50$ plaques ( $>5$ $\left.\mu \mathrm{m}^{2}\right)$ were more prominent in peripheral retina. $\boldsymbol{B}$, The sum of all $\mathrm{C} \times 50$ plaque areas increased slightly from central to peripheral retina (central, $4.2 \times 10^{4} \mu \mathrm{m}^{2} / \mathrm{mm}^{2}$; peripheral, $4.8 \times 10^{4} \mu \mathrm{m}^{2} / \mathrm{mm}^{2}$ ); also, the $\mathrm{C} \times 50$ plaque area per A-type $\mathrm{HC}$ was greater in peripheral inferior retina. C $x 50$ area per horizontal cell increased from 75 to $244 \mu \mathrm{m}^{2}$ per HC cell.
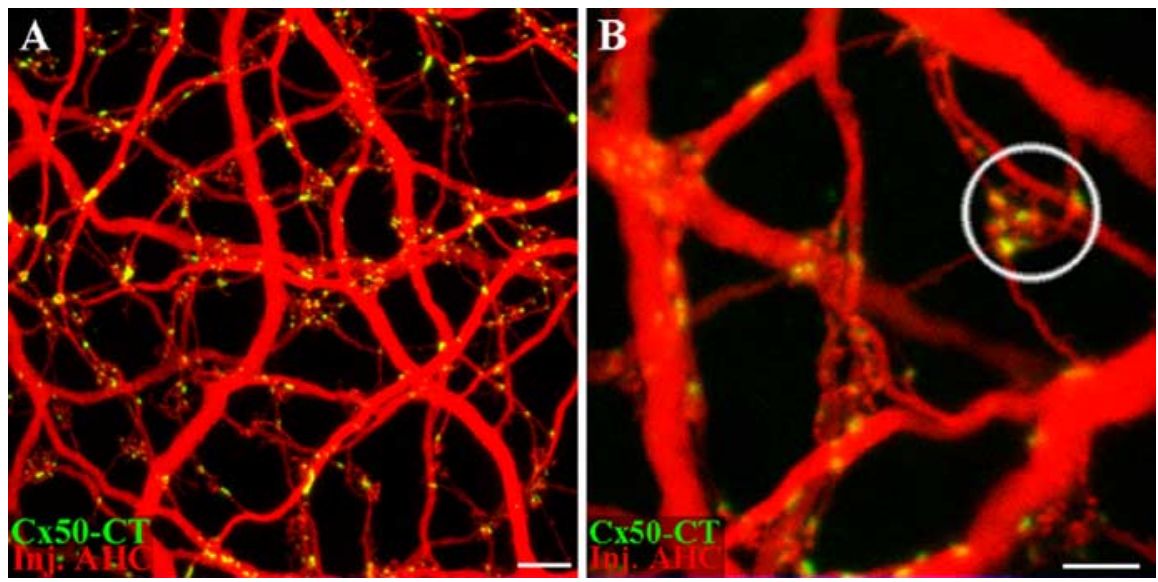

Figure 7. Cx50 plaques occur where fine A-type horizontal cell dendrites converge under cone pedicles. A, A-type HCs were filled with Neurobiotin to visualize the finer dendrites. $\mathrm{Xx} 50$ labeling was confined to the A-type HC network. Larger Cx50 plaques occurred at the intersection of major dendrites. Small $\mathrm{Cx} 50$ puncta occur where fine dendrites meet, often at terminal clusters associated with cones. $\boldsymbol{B}$, High-resolution view of a terminal cluster (circle). (x50 labeling is seen where fine dendrites converge underneath the cone pedicle. Scale bars: $A, 10 \mu \mathrm{m} ; \boldsymbol{B}, 5 \mu \mathrm{m}$. ized with A-type HCs. The presence of a few isolated Cx50 plaques is attributable to the difficulty of staining fine HC dendrites with the calbindin antibody.

We also performed a quantitative analysis of colocalization for Figure 10. In Figure $10 \mathrm{~B}, 96.8 \%$ of the $\mathrm{Cx} 50$ pixels (green) were colocalized with the calbindin signals in A-type HCs (blue). This is slightly less than $100 \%$ attributable to understaining of A-type HCs with the calbindin antibody. When the Cx50 image was rotated through $90^{\circ}$ increments, to destroy the registration between the two labels, the colocalization was reduced to $48.3 \%$. This represents the random overlap between two nonaligned images. In Figure $10 A$, $53 \%$ of the Cx50 pixels were colocalized with the Neurobiotin-filled B-type HCs (red). However, when the Cx50 channel was rotated through $90^{\circ}$ increments, the colocalization with B-type HCs was still $48.7 \%$. Thus, the apparent colocalization between Cx50 and B-type HCs was almost random, barely reduced by rotating one channel of the image out of alignment. If there is some slight preference for the original orientation, this could be attributable to cofasciculation in the OPL, where the dendrites of A-type and B-type HCs run together. This analysis indicates that essentially all of the Cx50 plaques are found on the dendrites of A-type HCs and not B-type HCs.

Finally, we used image analysis to select, align, and average structures of particular interest, in this case $\mathrm{Cx} 50$ plaques (Li et al., 2002). A sampling box was centered on each Cx50 plaque, and then the boxes were clipped from the image, aligned, and averaged. This gives the average structure for a repeated motif such as a gap junction. Then, the average distribution of the other channels around the selected structure can be determined. When evaluated, the Cx50 signal was correlated with the peak of the calbindin labeled 

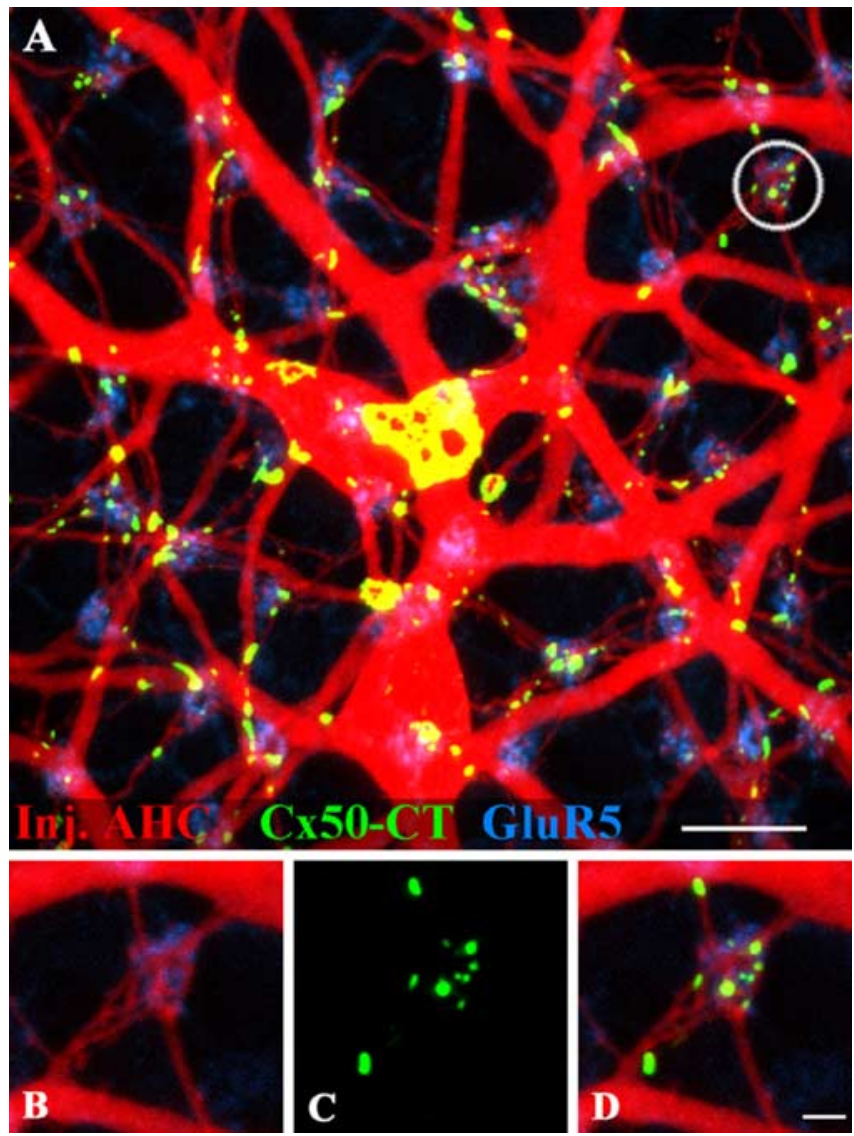

Figure 8. Cx50 plaques occur under cone pedicles at fine dendritic crossovers. A, A-type HCs in the inferior rabbit retina were filled with Neurobiotin (red). Several giant $\mathrm{C} \times 50$ plaques (green) occur at the intersections of large A-type $\mathrm{HC}$ dendrites. The giant $\mathrm{Cx} 50$ plaque in the center is $63 \mu \mathrm{m}^{2}$. The positions of the cone pedicles in the background are marked by staining OFF bipolar dendrites for GluR5 (blue). Small Cx50 plaques are close to many, but not all, cone pedicles. $\boldsymbol{B}$, High-resolution view of the circled area shows A-type $H C$ dendrites converging at a cone pedicle whose position is shown by GluR5 labeling. C, Small Cx50 plaques at the same location. $\boldsymbol{D}$, Triple-label image shows fine A-type $H C$ dendrites are interconnected by small $C \times 50$ gap junctions beneath the cone pedicle. Scale bars: $\boldsymbol{A}, 10 \mu \mathrm{m} ; \boldsymbol{B}-\boldsymbol{D}, 2 \mu \mathrm{m}$.

A-type HCs, but not the Neurobiotin-injected B-type HC (data not shown). When the A-type and B-type HC images were rotated $90^{\circ}$ out of phase, as a control, then neither cell type corresponded to the Cx50 peak signal. Thus, Cx50 is correlated with A-type but not B-type HCs, and this is consistent with the pixel analysis above. In turn, this suggests that B-type HCs use a different connexin, and this is consistent with results of dye-coupling experiments.

\section{Connexin 50 does not form plaques within the cone pedicle invagination}

Recently, it has been proposed that horizontal cell feedback to cones is mediated by hemichannels on the dendritic tips of horizontal cells, apposed to the cone pedicle membrane within the synaptic invagination (Kamermans et al., 2001). In a schematic cone pedicle, the processes of horizontal cells and ON cone bipolar cells are shown invaginating close to the synaptic ribbon [supplemental material, available at www.jneurosci.org; modified from Haverkamp et al. (2000)]. In contrast, OFF cone bipolar cells make basal synapses, some of which use kainate receptors at a distinctly different level (DeVries, 2000; Haverkamp et al., 2003). The proposed hemichannel locations are on the dendritic tips of the horizontal cell processes (supplemental material, avail- able at www.jneurosci.org; shown as yellow dots), whereas the locations of gap junctions between the converging dendrites of horizontal cells occur beneath the cone pedicle. To determine whether Cx50 is found at either of these locations, it is a simple matter to compare the relative position of the Cx50 labeling to the position of the OFF bipolar cell basal synapses, which can be marked with an antibody against GluR5. Hemichannel labeling should be above the basal synapses, and gap junction labeling should be below.

Vibratome sections were prepared from tissue in which several patches of A-type HCs had been dye injected with Neurobiotin. This approach was used because it is often difficult to see the fine details of dendritic structure in material stained for calbindin. The A-type HCs run throughout the outer plexiform layer, and at low power, Cx50 was distributed along the dendrites (Fig. 11). At higher magnification, when the positions of the cone pedicles were marked by GluR5, it can be seen that Cx50 labeling is often nearby (Fig. 11C). The positions of three individual cone pedicles are shown in Figure $11 D-G$. The A-type HC dendrites (red) protrude above the level of the basal synapses marked by GluR5 labeling (blue). The Cx50 labeling, shown in green, is colocalized on the A-type $\mathrm{HC}$ dendrites, but essentially all of the Cx50 occurs below the level of the OFF cone bipolar contacts. We could not detect Cx50 labeling on the A-type HC dendrites above the level of the basal synapses marked by GluR5.

In whole-mount retina, a focal series was taken of the region just below a cone pedicle. Single labels are shown for dye-injected A-type HCs, GluR5 labeled OFF cone bipolar cell dendrites and Cx50 in addition to the triple-labeled images (Fig. 12, last column). In the first row (Fig. 12A-D), the level of focus is on the dendritic tips of the A-type HCs. There is no labeling for GluR5 at this level because the A-type $\mathrm{HC}$ dendrites are higher within the cone pedicle invagination. There is also no Cx50 labeling at this level. In the second row (Fig. 12E-H), the focus is on the GluR5labeled contacts that mark the base of the cone pedicle. The A-type $\mathrm{HC}$ labeling is more extensive at this level, but again, there is almost no Cx50 labeling. In the third row (Fig. $12 \mathrm{I}-\mathrm{L}$ ), the focal plane is on the A-type $\mathrm{HC}$ dendrites where they converge beneath the cone pedicle. The GluR5 labeling is absent, but there is substantial Cx50 labeling. The final column of triple-label images (Fig. 12J-L) shows that, high within the invagination, there are only A-type $\mathrm{HC}$ dendrites (red). At the base of the cone pedicle, A-type HC dendrites and GluR5-labeled OFF bipolar dendrites are interspersed. And, finally, beneath the cone pedicle, there is extensive colocalization of $\mathrm{Cx} 50$ in the A-type HC dendrites. In summary, we were unable to detect Cx50 labeling on the dendritic tips of A-type HCs within the cone pedicle invagination. Rather, Cx50 gap junctions are found on the A-type HC matrix below the cone pedicle base. These results do not support a role for $\mathrm{Cx} 50$ in the hemichannel-mediated mechanism of horizontal cell feedback.

\section{Connexin 50 in A-type horizontal cells of the cat retina}

The cat retina also contains both A-type and B-type HCs, similar to the rabbit retina (Boycott et al., 1978). In contrast, the mouse retina only contains only one type of horizontal cell similar to B-type HCs (Peichl and Gonzalez-Soriano, 1994). A supplemental figure (available at www.jneurosci.org as supplemental material) shows a region of cat retina double labeled with calbindin and Cx50. The thick primary dendrites of the cat A-type HCs are clearly visible, crossing each other. In addition to the thick primary dendrites, some finer secondary dendrites are also stained for calbindin. When the distribution of $\mathrm{Cx} 50$ was examined in the 

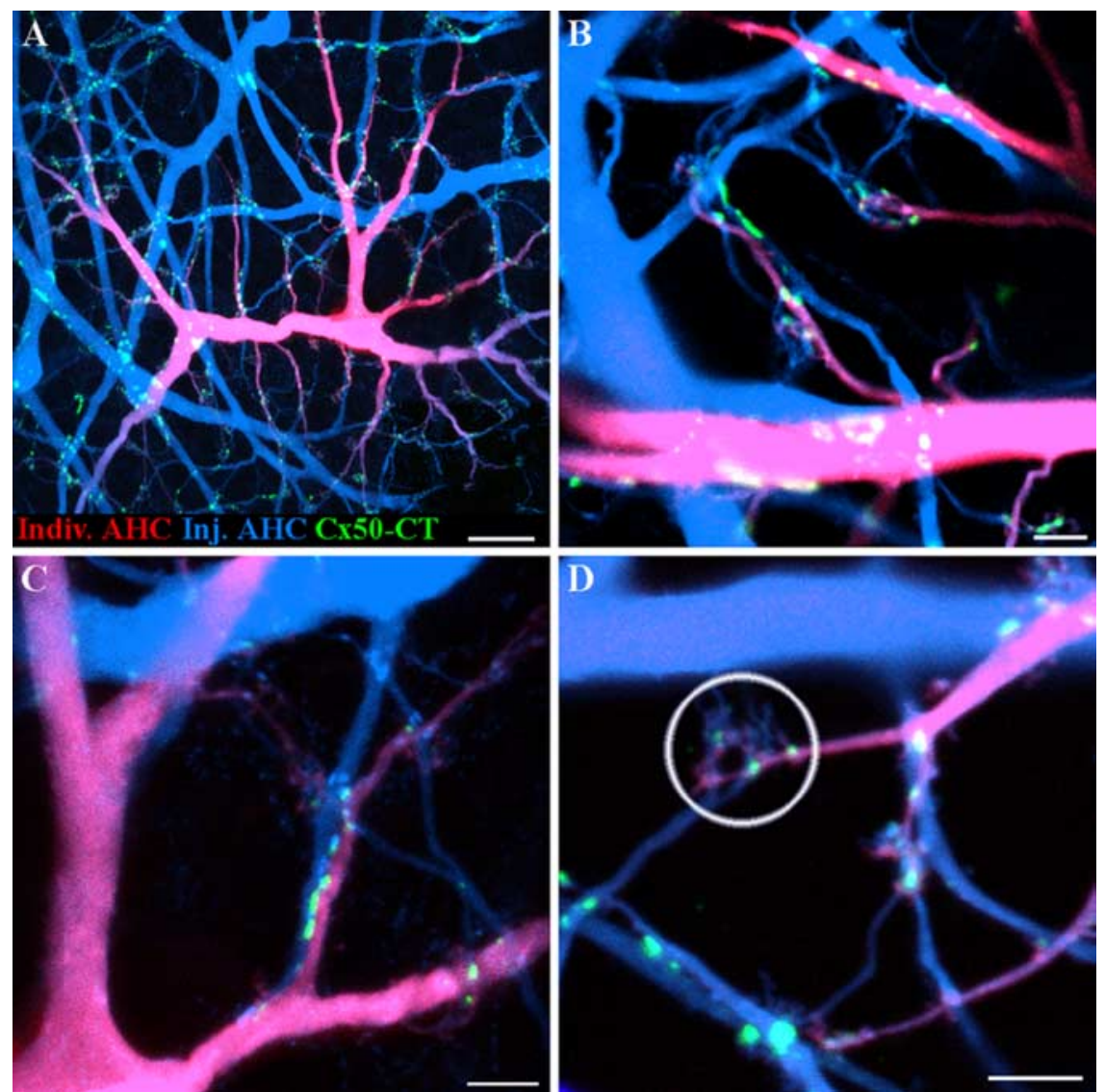

Figure 9. Two dye experiments show Cx50 gap junctions at contact points between different A-type horizontal cells. $\boldsymbol{A}$, An A-type HC was injected with an Alexa 568 hydrazide (red), and the surrounding A-type $H C$ network was filled with Neurobiotin (blue). Cx50 plaques (green) occur where individual dendrites of one A-type HC contact another A-type HC. $\boldsymbol{B}$, In a different pair, Cx50 forms gap junction plaques where a small dendrite crosses another of large diameter. $C, C \times 50$ forms a linear row of gap junctions where two $A$-type dendrites contact as they run in parallel. This picture is enlarged from $\boldsymbol{A}$. $\boldsymbol{D}$, In another pair of cells, $\mathrm{C} \times 50$ forms gap junction puncta where A-type HCs converge under a cone pedicle (circled). Scale bars: $\boldsymbol{A}, 20 \mu \mathrm{m} ; \boldsymbol{B}-\boldsymbol{D}, 5 \mu \mathrm{m}$.
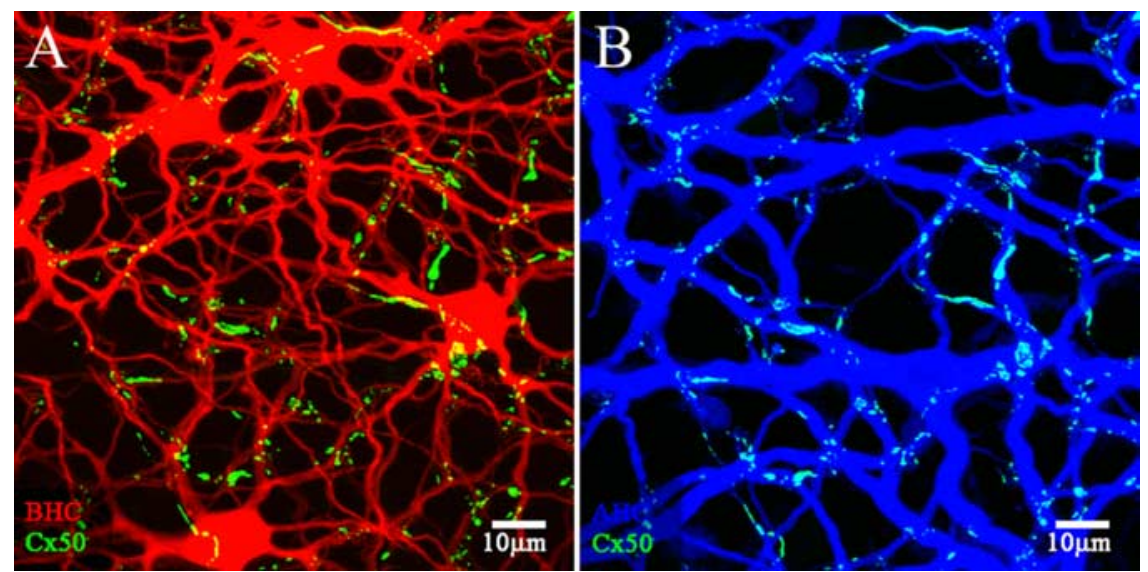

Figure 10. B-type horizontal cells do not express $C \times 50 . A$, A patch of coupled B-type HCs was filled with Neurobiotin (red). Cx50 plaques (green) did not colocalize with B-type HCs. Shown is a confocal stack through the OPL, $37 \times 0.3 \mu$ m optical sections. $\boldsymbol{B}$, The same field showing A-type HCs stained with an antibody against calbindin (blue). Cx50 plaques (green) are almost entirely colocalized within the matrix of A-type HCs and thus appear cyan (green plus blue). A few apparently isolated Cx50 plaques were associated with lightly stained fine A-type $\mathrm{HC}$ dendrites (see Results). Scale bars, $10 \mu \mathrm{m}$.

cat retina, Cx50 plaques were found on the A-type HC network at dendritic intersections. Additionally, the Cx50 plaques in the cat retina had a similar size distribution, from small puncta on fine dendritic crossings to large plaques at the intersections of pri- mary dendrites. Thus, Cx50 may account for coupling between axonless horizontal cells in other mammalian species in addition to the rabbit.

\section{Discussion}

It is becoming clear that electrical synapses constructed from connexins are important network components with specific functional properties in the mammalian retina. In this paper, we describe the distribution of Cx50 in A-type HCs in the rabbit retina. The size and number of Cx50 gap junctions are consistent with the extensive coupling of the A-type horizontal cell network.

Gap junctions in the A-type horizontal cell network contain connexin $\mathbf{5 0}$ In this type of study, it is important to establish the specificity of the antibody used to locate Cx50. Although the C-terminal antibody that we used recognized a sequence common to Cx40 and Cx50, Western blot analysis showed that only Cx50 was expressed in the rabbit retina. Furthermore, the antibody was shown to recognize Cx50 from the lens and an antibody against the intracellular loop of Cx50 labeled the same structures as the C-terminal antibody. When two antibodies against different portions of a sequence (in this case, $\mathrm{C}$ terminus and intracellular loop) recognize the same target, this represents strong evidence for antibody specificity. RT-PCR using dissociated A-type HCs also identified Cx50, as reported previously (Huang et al., 2005). In summary, these results indicate that the C-terminal antibody was specific to Cx50 and could be used in immunolocalization studies.

Of all of the structures in the retina, only A-type HCs were positive for Cx50. Cx50 plaques were found at dendritic crossings and contact points in the A-type $\mathrm{HC}$ matrix. The presence of large plaques at junctions between major dendrites was particularly noticeable. This kind of connexin staining pattern, also reported for Cx36 at dendritic crossings in the AII amacrine cell matrix, is diagnostic for gap junction labeling (Mills et al., 2001).

\section{Distribution and size of $\mathrm{Cx} 50$ can account for the extensive A-type HC coupling}

It is instructive to estimate the coupling that may result from the $\mathrm{Cx} 50$ gap junctions between A-type HCs. In a gap junction plaque, the center-to-center spacing of individual connexins is $\sim 10 \mathrm{~nm}$. Thus, each channel occupies $\sim 100 \mathrm{~nm}^{2}$ at a density of $\sim 10,000$ channels/ $\mu \mathrm{m}^{2}$ (Caspar et al., 1977; Peracchia, 1977; Bukauskas et al., 2000). The giant plaques 
have significant substructure and spacing; however, this extra space is eliminated in the size analysis because only contiguous pixels are included. Thus, for a giant plaque of $52 \mu \mathrm{m}^{2}$ in central retina, there are $\sim 520,000$ channels. However, the gating properties mean that the channels are not all open at the same time. It has been estimated that $<2 \%$ of channels are open in a small gap junction plaque, but that as much as $10-20 \%$ of channels are open for plaques of $0.5 \mu \mathrm{m}$ in diameter $\left(0.25 \mu \mathrm{m}^{2}\right)$ (Bukauskas et al., 2000). If $2 \%$ of the channels are open, then there are $\sim 10,400$ open channels in a $52 \mu \mathrm{m}^{2}$ giant Cx50 plaque. Because $\mathrm{Cx} 50$ has a high unitary conductance of $220 \mathrm{pS}$ (Srinivas et al., 1999), a giant Cx50 plaque may have a plaque conductance of $2.29 \mu \mathrm{S}$. This suggests the transjunctional resistance across a $52 \mu \mathrm{m}^{2} \mathrm{Cx} 50$ plaque may be as low as $0.44 \mathrm{M} \Omega$. Although the estimates of plaque size may be subject to systematic errors, especially for the smallest sizes, there can be little doubt that the giant Cx50 plaques reported here must have a very low transjunctional resistance.

We also calculated the total $\mathrm{Cx} 50$ plaque density, which, divided by the local density of A-type HCs, yielded $113 \mu \mathrm{m}^{2}$ of $\mathrm{Cx} 50$ gap junctional area per A-type $\mathrm{HC}$ in the central retina. All of the Cx50 gap junctions occur between A-type HCs, so the total gap junction conductance between a single A-type $\mathrm{HC}$ and the immediate neighbors may be as high as $5 \mu \mathrm{S}$, equivalent to an extremely low coupling resistance of $0.2 \mathrm{M} \Omega$. Dividing by the coverage, which is $\sim 6$ in central retina, gives an estimate of $\sim 1 \mathrm{M} \Omega$ transjunctional resistance between two neighboring A-type HCs. In addition, the distribution of Cx50 plaques suggests that horizontal cells may show increased coupling in the peripheral retina. These calculations, although necessarily approximate, suggest that the gap junctions formed by $\mathrm{Cx} 50$ have an extremely low resistance and may account for the extensive coupling between A-type horizontal cells.

\section{The staining pattern does not support a role for Cx50 in a} hemichannel mechanism for horizontal cell feedback to cones In the absence of a conventional explanation for horizontal cell feedback, an alternative ephaptic mechanism, based on the presence of hemichannels, has been proposed. In this model, open hemichannels, expressed in the tips of horizontal cell dendrites, pass sufficient current to change the voltage across the presynaptic membrane, resulting in an increased calcium current, close to the synaptic ribbon. This will alter the release of glutamate from the cone pedicle (Kamermans et al., 2001). In order for this to occur, connexins must be located at the tip of the horizontal cell dendrite.

Our anatomical data provide no direct evidence to support a role for Cx50 in hemichannel-mediated feedback. First, we could not detect $\mathrm{Cx} 50$ at the tips of A-type $\mathrm{HC}$ dendrites within the cone invagination. Rather, triple-label experiments showed that Cx50 plaques occurred beneath the base of the cone pedicle, not higher apposed to the cone pedicle membrane. Second, Cx50 plaques were always found to occur between two crossed or ad- jacent A-type HC dendrites. The position of small Cx50 plaques beneath the cone pedicles was attributable to gap junctions between fine dendrites from different A-type HCs, as they converged at individual cone pedicles. We never found unapposed Cx50 plaques in isolated dendrites. In summary, the data in this paper clearly demonstrate that Cx50 gap junctions occur at dendritic contact points in the matrix of A-type HCs. We also detected faint and diffuse Cx50 labeling in the major dendrites of A-type HCs, which may represent the trafficking of hemichannels in the cell membrane. It is possible that hemichannels diffuse throughout the entire cell, but we were unable to detect any Cx50 signal on A-type $\mathrm{HC}$ dendrites within the cone pedicle invagination. Although our data do not support a role for $\mathrm{Cx} 50$, we cannot rule out contributions from other connexins should they be expressed by A-type HCs.

\section{Cx50 regulation and horizontal cell modulation have some similar properties}

Cx50 occurs primarily in the lens where it forms gap junctions between lens fiber cells. Furthermore, mutations in Cx50 result in cataract formation in the lens (White et al., 1998). Similar to A-type HCs, lens fibers also exhibit tracer coupling with Lucifer yellow (Tenorio et al., 1996). The open/closed state of $\mathrm{Cx} 50$ is $\mathrm{pH}$ dependent over a narrow range and channels close in an acidic environment (Xu and Yang, 2002). The $\mathrm{pH}$ sensitivity is primarily located in the $\mathrm{C}$ terminus, which is naturally truncated within the lens core to facilitate homeostasis (Lin et al., 1998; Xu and Yang, 2002).

The $\mathrm{pH}$ sensitivity of $\mathrm{Cx} 50$ may be significant because the uncoupling of A-type HCs in the rabbit retina in response to 


\section{Horiz. Cell Dendritic Tips}

\section{Base of \\ Cone Pedicle}

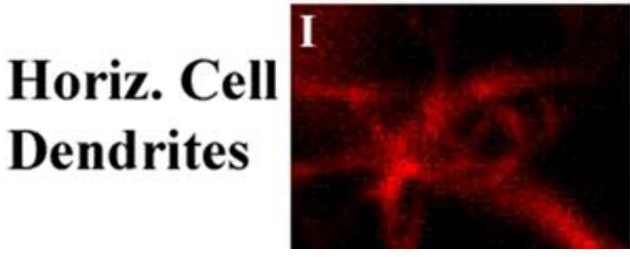

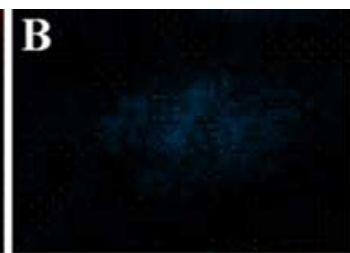
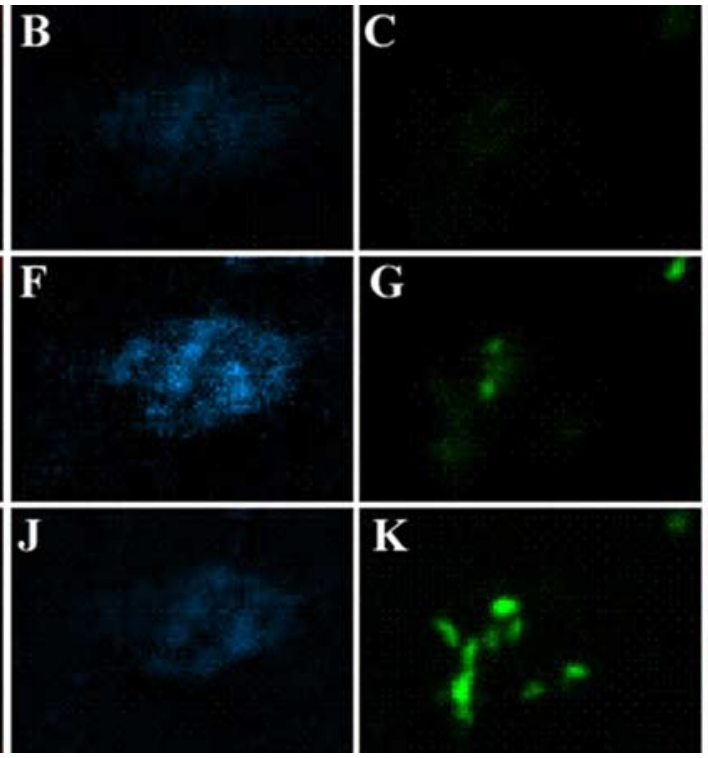

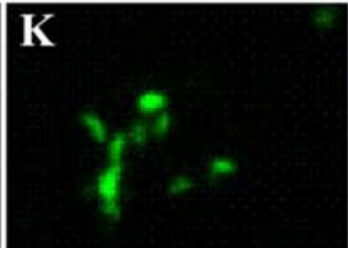

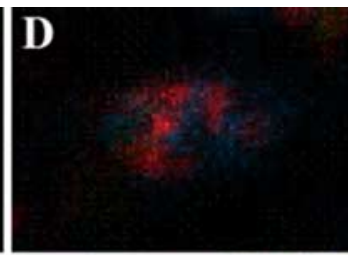
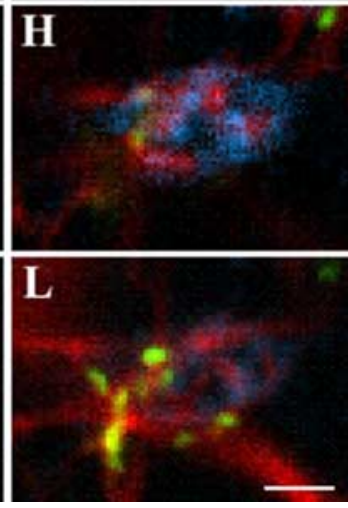

Figure 12. Cx50 plaques occur below the cone pedicle where horizontal cell dendrites converge. Different focal planes of whole-mount retina, near a cone pedicle, are shown. A-type $\mathrm{HC}$ dendrites were scanned every $0.2 \mu \mathrm{m}$ after injection of Neurobiotin (red) and staining with Cx50 (green) and GluR5 (blue). $\boldsymbol{A}-\boldsymbol{D}$, At the level of the horizontal cell tips, high within the cone pedicle invagination, there was no GluR5 (B) or x50 labeling ( $\boldsymbol{C}$. The triple-label image $(\boldsymbol{D})$ shows only horizontal cell dendrites. $\boldsymbol{E}-\boldsymbol{H}$, At the base of the cone pedicle, marked by the staining of GluR5-labeled OFF bipolar dendrites $(\boldsymbol{F})$, there was a little $\mathrm{Cx} 50$ staining $(\boldsymbol{G})$, colocalized with A-type $\mathrm{HC}$ dendrites. In the triple-label image $(\boldsymbol{H})$, the dendrites of 0 FF cone bipolar cells and A-type $\mathrm{HC}$ are interspersed, not colocalized. $\boldsymbol{I}-\boldsymbol{L}$, Below the base of the cone pedicle, A-type HC dendrites converge $(\boldsymbol{I})$, there is no $\mathrm{GluR5}$ labeling $(\boldsymbol{J})$, and there are prominent $\mathbf{C x} 50$ plaques $(\boldsymbol{K})$. The triple-label image shows that the Cx50 plaques occur at dendritic crossings and contacts in the matrix of A-type HC dendrites ( $\boldsymbol{L}$ ). Scale bar: $\boldsymbol{A}-\boldsymbol{L}, 2 \mu \mathrm{m}$.

exogenous dopamine only occurs within a narrow acidic $\mathrm{pH}$ range (Hampson et al., 1994). Furthermore, the fluctuation of $\mathrm{pH}$ in the outer plexiform layer has a circadian rhythm (Dmitriev and Mangel, 2001). This suggests a possible mechanism whereby A-type $\mathrm{HC}$ coupling could also be regulated in a circadian cycle.

\section{Multiple neuronal connexins are expressed in the} rabbit retina

In this paper, for the first time, we have demonstrated the presence of Cx50 gap junctions in neurons. The expression of Cx50 in A-type HCs appears to be common to both rabbit and cat retinas, suggesting that $\mathrm{Cx} 50$ gap junctions may be cell type specific. In contrast, the axon-bearing B-type $\mathrm{HC}$, which also forms a coupled network, does not express $\mathrm{Cx} 50$. In the mouse retina, which has only one axon-bearing type of horizontal cell analogous to the rabbit B-type, Cx57 was expressed in horizontal cells, and in a Cx57 knock-out, there was no coupling in the horizontal cell matrix (Peichl and Gonzalez-Soriano, 1994; Hombach et al., 2004). This may suggest that B-type HCs in the rabbit retina also express Cx57. Because the two kinds of horizontal cell in the rabbit overlap extensively in the outer plexiform layer, the expression of different connexins may ensure specificity between the two independent networks. In addition, the large conductance of Cx50 channels and the large size of the Cx50 plaques are responsible for the much greater degree of coupling in the A-type HC network.

Thus, it is now clear that there are multiple neuronal connexins that are responsible for coupling in different neuronal networks. In addition to $\mathrm{Cx} 50$ and $\mathrm{Cx} 57$, which appear to be specific to horizontal cells, the retina also uses Cx36 and Cx45. Cx36 is localized to AII amacrine cells and photoreceptors, among other cells, whereas Cx45 is expressed in bipolar cells and bistratified ganglion cells (Feigenspan et al., 2001, 2004; Mills et al., 2001; Lee et al., 2003; Maxeiner et al., 2005; Schubert et al., 2005; Volgyi et al., 2005). Thus, four neuronal connexins have been identified in the mammalian retina: $\mathrm{Cx} 36$ (the dominant neuronal connexin), Cx45, Cx50, and Cx57.

\section{References}

Ames III A, Nesbett FB (1981) In vitro retina as an experimental model of the central nervous system. J Neurochem 37:867-877.

Beyer EC, Reed KE, Westphale EM, Kanter HL, Larson DM (1992) Molecular cloning and expression of rat connexin40, a gap junction protein expressed in vascular smooth muscle. J Membr Biol 127:69-76.

Bloomfield SA, Miller RF (1982) A physiological and morphological study of the horizontal cell types of the rabbit retina. J Comp Neurol 208:288-303

Bloomfield SA, Xin D, Persky SE (1995) A comparison of receptive field and tracer coupling size of horizontal cells in the rabbit retina. Vis Neurosci 12:985-999.

Boycott BB, Peichl L, Wässle H (1978) Morphological types of horizontal cell in the retina of the domestic cat. Proc R Soc Lond B Biol Sci 203:229-245.

Bukauskas FF, Jordan K, Bukauskiene A, Bennett MV, Lampe PD, Laird DW, Verselis VK (2000) Clustering of connexin 43-enhanced green fluorescent protein gap junction channels and functional coupling in living cells. Proc Natl Acad Sci USA 97:2556-2561.

Caspar DL, Goodenough DA, Makowski L, Phillips WC (1977) Gap junction structures. I. Correlated electron microscopy and $\mathrm{x}$-ray diffraction. J Cell Biol 74:605-628.

Chandross KJ, Spray DC, Cohen RI, Kumar NM, Kremer M, Dermietzel R, Kessler JA (1996) TNF alpha inhibits Schwann cell proliferation, connexin46 expression, and gap junctional communication. Mol Cell Neurosci 7:479-500.

Dacheux RF, Raviola E (1982) Horizontal cells in the retina of the rabbit. J Neurosci 2:1486-1493.

Deans MR, Paul DL (2001) Mouse horizontal cells do not express connexin26 or connexin36. Cell Adhes Commun 8:361-366.

Deans MR, Volgyi B, Goodenough DA, Bloomfield SA, Paul DL (2002) Connexin36 is essential for transmission of rod-mediated visual signals in the mammalian retina. Neuron 36:703-712.

DeVries SH (2000) Bipolar cells use kainate and AMPA receptors to filter visual information into separate channels. Neuron 28:847-856.

DeVries SH, Schwartz EA (1989) Modulation of an electrical synapse be- 
tween solitary pairs of catfish horizontal cells by dopamine and second messengers. J Physiol (Lond) 414:351-375.

DeVries SH, Schwartz EA (1992) Hemi-gap-junction channels in solitary horizontal cells of the catfish retina. J Physiol (Lond) 445:201-230.

Dmitriev AV, Mangel SC (2001) Circadian clock regulation of $\mathrm{pH}$ in the rabbit retina. J Neurosci 21:2897-2902.

Feigenspan A, Teubner B, Willecke K, Weiler R (2001) Expression of neuronal connexin36 in AII amacrine cells of the mammalian retina. J Neurosci 21:230-239.

Feigenspan A, Janssen-Bienhold U, Hormuzdi S, Monyer H, Degen J, Sohl G, Willecke K, Ammermuller J, Weiler R (2004) Expression of connexin36 in cone pedicles and OFF-cone bipolar cells of the mouse retina. J Neurosci 24:3325-3334.

Goodenough DA, Paul DL (2003) Beyond the gap: functions of unpaired connexon channels. Nat Rev Mol Cell Biol 4:285-294.

Gros D, Jarry-Guichard T, Ten Velde I, de Maziere A, van Kempen MJ, Davoust J, Briand JP, Moorman AF, Jongsma HJ (1994) Restricted distribution of connexin 40, a gap junctional protein, in mammalian heart. Circ Res 74:839-851.

Guldenagel M, Sohl G, Plum A, Traub O, Teubner B, Weiler R, Willecke K (2000) Expression patterns of connexin genes in mouse retina. J Comp Neurol 425:193-201.

Hampson EC, Weiler R, Vaney DI (1994) pH-gated dopaminergic modulation of horizontal cell gap junctions in mammalian retina. Proc R Soc Lond B Biol Sci 255:67-72.

Haverkamp S, Grunert U, Wassle H (2000) The cone pedicle, a complex synapse in the retina. Neuron 27:85-95.

Haverkamp S, Grunert U, Wässle H (2001) Localization of kainate receptors at the cone pedicles of the primate retina. J Comp Neurol 436:471-486.

Haverkamp S, Ghosh KK, Hirano AA, Wässle H (2003) Immunocytochemical description of five bipolar cell types of the mouse retina. J Comp Neurol 455:463-476.

He S, Weiler R, Vaney DI (2000) Endogenous dopaminergic regulation of horizontal cell coupling in the mammalian retina. J Comp Neurol 418:33-40.

Hennemann H, Suchyna T, Lichtenberg-Frate H, Jungbluth S, Dahl E, Schwarz J, Nicholson BJ, Willecke K (1992) Molecular cloning and functional expression of mouse connexin40, a second gap junction gene preferentially expressed in lung. J Cell Biol 117:1299-1310.

Hombach S, Janssen-Bienhold U, Sohl G, Schubert T, Bussow H, Ott T, Weiler R, Willecke K (2004) Functional expression of connexin57 in horizontal cells of the mouse retina. Eur J Neurosci 19:2633-2640.

Huang H, Li H, He SG (2005) Identification of connexin 50 and 57 mRNA in A-type horizontal cells of the rabbit retina. Cell Res 15:207-211.

Kamermans M, Fahrenfort I, Schultz K, Janssen-Bienhold U, Sjoerdsma T, Weiler R (2001) Hemichannel-mediated inhibition in the outer retina. Science 292:1178-1180.

Kanter HL, Saffitz JE, Beyer EC (1994) Molecular cloning of two human cardiac gap junction proteins, connexin40 and connexin45. J Mol Cell Cardiol 26:861-868.

Kolb H (1977) The organization of the outer plexiform layer in the retina of the cat: electron microscopic observations. J Neurocytol 6:131-153.

Lauf U, Giepmans BN, Lopez P, Braconnot S, Chen SC, Falk MM (2002) Dynamic trafficking and delivery of connexons to the plasma membrane and accretion to gap junctions in living cells. Proc Natl Acad Sci USA 99:10446-10451.

Lee EJ, Han JW, Kim HJ, Kim IB, Lee MY, Oh SJ, Chung JW, Chun MH (2003) The immunocytochemical localization of connexin 36 at rod and cone gap junctions in the guinea pig retina. Eur J Neurosci 18:2925-2934.

Li W, DeVries SH (2004) Separate blue and green cone networks in the mammalian retina. Nat Neurosci 7:751-756.

Li W, Trexler EB, Massey SC (2002) Glutamate receptors at rod bipolar ribbon synapses in the rabbit retina. J Comp Neurol 448:230-248.

Lin JS, Fitzgerald S, Dong Y, Knight C, Donaldson P, Kistler J (1997) Processing of the gap junction protein connexin 50 in the ocular lens is accomplished by calpain. Eur J Cell Biol 73:141-149.

Lin JS, Eckert R, Kistler J, Donaldson P (1998) Spatial differences in gap junction gating in the lens are a consequence of connexin cleavage. Eur J Cell Biol 76:246-250.

Massey SC, Mills SL (1996) A calbindin-immunoreactive cone bipolar cell type in the rabbit retina. J Comp Neurol 366:15-33.
Matesic D, Tillen T, Sitaramayya A (2003) Connexin 40 expression in bovine and rat retinas. Cell Biol Int 27:89-99.

Maxeiner S, Dedek K, Janssen-Bienhold U, Ammermuller J, Brune H, Kirsch T, Pieper M, Degen J, Kruger O, Willecke K, Weiler R (2005) Deletion of connexin45 in mouse retinal neurons disrupts the rod/cone signaling pathway between AII amacrine and ON cone bipolar cells and leads to impaired visual transmission. J Neurosci 25:566-576.

Mills SL, Massey SC (1991) Labeling and distribution of AII amacrine cells in the rabbit retina. J Comp Neurol 304:491-501.

Mills SL, Massey SC (1994) Distribution and coverage of A- and B-type horizontal cells stained with Neurobiotin in the rabbit retina. Vis Neurosci 11:549-560.

Mills SL, Massey SC (1998) The kinetics of tracer movement through homologous gap junctions in the rabbit retina. Vis Neurosci 15:765-777.

Mills SL, Massey SC (2000) A series of biotinylated tracers distinguishes three types of gap junction in retina. J Neurosci 20:8629-8636.

Mills SL, O'Brien JJ, Li W, O'Brien J, Massey SC (2001) Rod pathways in the mammalian retina use connexin36. J Comp Neurol 436:336-350.

Nelson R, von Litzow A, Kolb H, Gouras P (1975) Horizontal cells in cat retina with independent dendritic systems. Science 189:137-139.

Peichl L, Gonzalez-Soriano J (1994) Morphological types of horizontal cell in rodent retinae: a comparison of rat, mouse, gerbil, and guinea pig. Vis Neurosci 11:501-517.

Peracchia C (1977) Gap junctions. Structural changes after uncoupling procedures. J Cell Biol 72:628-641.

Raviola E, Dacheux RF (1990) Axonless horizontal cells of the rabbit retina: synaptic connections and origin of the rod aftereffect. J Neurocytol 19:731-736.

Raviola E, Gilula NB (1975) Intramembrane organization of specialized contacts in the outer plexiform layer of the retina. A freeze-fracture study in monkeys and rabbits. J Cell Biol 65:192-222.

Rohrenbeck J, Wassle H, Heizmann CW (1987) Immunocytochemical labelling of horizontal cells in mammalian retina using antibodies against calcium-binding proteins. Neurosci Lett 77:255-260.

Schubert T, Maxeiner S, Kruger O, Willecke K, Weiler R (2005) Connexin45 mediates gap junctional coupling of bistratified ganglion cells in the mouse retina. J Comp Neurol 490:29-39.

Sohl G, Degen J, Teubner B, Willecke K (1998) The murine gap junction gene connexin 36 is highly expressed in mouse retina and regulated during brain development. FEBS Lett 428:27-31.

Srinivas M, Costa M, Gao Y, Fort A, Fishman GI, Spray DC (1999) Voltage dependence of macroscopic and unitary currents of gap junction channels formed by mouse connexin50 expressed in rat neuroblastoma cells. J Physiol (Lond) 517:673-689.

Tenorio F, Giraldi-Guimaraes A, Mendez-Otero R (1996) Morphology of NADPH-diaphorase-positive cells in the retinoceptive layers of the developing rat superior colliculus. Int J Dev Neurosci 14:1-10.

Teranishi T, Negishi K, Kato S (1984) Regulatory effect of dopamine on spatial properties of horizontal cells in carp retina. J Neurosci 4:1271-1280.

Vaney DI (1991) Many diverse types of retinal neurons show tracer coupling when injected with biocytin or Neurobiotin. Neurosci Lett 125:187-190.

Vaney DI (1993) The coupling pattern of axon-bearing horizontal cells in the mammalian retina. Proc R Soc Lond B Biol Sci 252:93-101.

Volgyi B, Abrams J, Paul DL, Bloomfield SA (2005) Morphology and tracer coupling pattern of alpha ganglion cells in the mouse retina. J Comp Neurol 492:66-77.

Wässle H (2004) Parallel processing in the mammalian retina. Nat Rev Neurosci 5:747-757.

White TW, Bruzzone R, Goodenough DA, Paul DL (1992) Mouse Cx50, a functional member of the connexin family of gap junction proteins, is the lens fiber protein MP70. Mol Biol Cell 3:711-720.

White TW, Goodenough DA, Paul DL (1998) Targeted ablation of connexin50 in mice results in microphthalmia and zonular pulverulent cataracts. J Cell Biol 143:815-825.

Xin D, Bloomfield SA (1999) Dark- and light-induced changes in coupling between horizontal cells in mammalian retina. J Comp Neurol 405:75-87.

Xu H-P, Yang X-L (2002) Different effects of low $\mathrm{Ca}^{2+}$ on signal transmission from rods and cones to bipolar cells in carp retina. Brain Res 957:136-143.

Zampighi GA, Plannells AM, Lin D, Takemoto D (2005) Regulation of lens cell-to-cell communication by activation of PKCgamma and disassembly of Cx50 channels. Invest Ophthalmol Vis Sci 46:3247-3255. 